Article

\title{
Asymptotic Output Tracked Artificial Immunity Controller for Eco-Maximum Power Point Tracking of Wind Turbine Driven by Doubly Fed Induction Generator
}

\author{
Marwa Hassan ${ }^{1, *}$, Alsnosy Balbaa ${ }^{2}$, Hanady H. Issa ${ }^{2} \mathbb{D}$ and Noha H. El-Amary ${ }^{2, *(D)}$ \\ 1 Computer, Control and Operation Research Department, Piazzale Aldo Moro, Sapienza University, \\ 00185 Rome, Italy \\ 2 Arab Academy for Science, Technology and Maritime Transport (AASTMT), Cairo 2033, Egypt; \\ hotmail222@yahoo.com (A.B.); hanady.issa@aast.edu (H.H.I.) \\ * Correspondence: marwa.hassan@uniroma1.it (M.H.); noha_helamary@hotmail.com (N.H.E.-A.)
}

Received: 24 August 2018; Accepted: 27 September 2018; Published: 2 October 2018

\begin{abstract}
This paper aims to design a controller for a Doubly Fed Induction Generator (DFIG) targeting the Eco-Maximum Power Point Tracking (EMPPT) for environmental aspects. The proposed controller consists of two clusters, which are the novel Artificial Immunity sensorless Eco-Maximum Power Point Tracking (AI EMPPT) and the asymptotic non-linear control techniques. The main target of the AI EMPPT is to reduce the carbon dioxide emission by generating the maximum possible power from the renewable electrical energy resource, which is wind electrical power generation to replace the fossil-fuel conventional generation. To build the AI EMPPT, an Artificial Immunity System Estimator (AISE) based on artificial immunity technique and a Model Reference Adaptive System (MRAS) are used to estimate the DFIG rotor speed. Then, the AI EMPPT is applied to provide the reference electromagnetic torque signal. Subsequently, the reference electromagnetic torque interacts with the estimated generator speed, determined by the wind mechanical power, to supply the wind electrical power. The second cluster is the asymptotic non-linear control technique which proposes the reference signal tracking of the rotor direct and quadratic current, respectively. Thus, assigning specific zeros through feedback ensures the reproduction of an output that converges asymptotically to a required reference rotor current. For online operation, the Artificial Immunity Technique (AIT) is utilized to deal with the generated control reference signal. A proposal hardware implementation on Field Programmed Gate Array (FPGA) is also presented. The introduced approach was applied to a wind turbine generator driving a $3.7 \mathrm{~kW}$ load. MATLAB program was used to simulate and test the performance of the proposed control methods. The results to show the effectiveness of the proposed technique. The reduction in $\mathrm{CO}_{2}$ emission was calculated.
\end{abstract}

Keywords: artificial Immunity eco-maximum power point tracking (AI EMPPT); artificial immunity system estimator (AISE); asymptotic output tracking; doubly fed induction generator (DFIG); field programmed gate array (FPGA); non-linear control (NLC); renewable energy; rotor side converter

\section{Introduction}

Traditional energy sources such as fossil fuel face critical problems regarding their prices and reducing Carbon dioxide emissions [1]. Accordingly, it is essential to search for alternative energy sources. In the last decade, renewable energy has drawn attention as it provides clean and inexhaustible energy. The main advantage of this energy is the ability to implement it anywhere on the planet. 
In addition, renewable energy sources differ from traditional fossil fuel regarding their diversity and abundance. Moreover, their costs are also falling at a sustainable rate, whereas the general cost trend for fossil fuels is in the opposite direction despite their present volatility. Wind energy is considered one of the most effective renewable sources [2-8]. It has many advantages as it is abundant and nondepletable. In fact, it is estimated that, by the end of 2020, renewable electricity generation will grow by over one third to $>8000$ terawatts per hour to be equal to the total consumption of India, China, and Germany [9]. Even though there has been significant growth in integrating wind energy into power grids, there are still issues in the design of Wind Energy Conversion System (WECS). One of the most common problems that face researchers when dealing with wind system is the difficulty of obtaining a direct measurement of wind speed due to wind speed variations at different points over the blades swept area $[10,11]$. Mechanical sensors can be used to overcome this obstacle, but this will increase the cost of both equipment and maintenance [12]. An alternative solution is to analyze the wind speed effectiveness through utilizing indirect methods, which requires studying other signals such as electric torque, output power and generator rotor speed [13-16]. Even though these techniques succeed in finding a solution to the problem, they still have some drawbacks due to the non-linearity found in wind turbine modeling. In latest years, extensive research has been carried out to estimate the wind speed. Most studies are based on system identification, data mining [17] and artificial intelligent techniques such as immunity, fuzzy, neural network and neuro-fuzzy [18-23]. An approach based on neuro-fuzzy method is introduced in [23], where the wind speed profiles up to $100 \mathrm{~m}$ height is estimated and controlled. The main disadvantage of this work is the cost that results from the use of sensors.

Non-linear control technique is designed to control the rotor current of the DFIG. DFIG generators have numerous advantages over their counterparts. When compared to another type of generator used in wind system, the DFIG provides better results concerning weight, cost, and size. It also presents more significant benefits such as power quality and efficiency $[24,25]$. In general, the standard structure of wind turbines consists of a DFIG, a wound rotor induction generator and an AC/DC/AC converter. The stator winding is connected directly to the grid while the rotor is fed at variable frequency through the AC/DC/AC converter. The DFIG technology allows extracting maximum energy from the wind. For low wind speeds, optimizing the turbine speed occurs by minimizing the mechanical stresses on the turbine during gusts of wind [26]. The first focus is on the estimated DFIG speed.

The signal of the rotor speed can be determined through several methods such as a speed sensor or by using a speed estimator. Both techniques suffer from some problems. The use of a sensor and a connection cable in the speed sensor technique causes issues regarding the budget while the accuracy of the speed estimation determined using the speed estimator technique will depend on the machine [27]. Another problem is if the generator operates around synchronous speed, its rotor will be excited with low-frequency voltages, and the integrator cannot give an accurate output value [28]. In this paper, we propose an Artificial Immunity System Estimator (AISE) which is utilized to estimate the rotor speed. The AISE considers the errors from machine parameters variation. The AISE consists of Model Reference Adaptive System (MRAS) and Artificial Immunity (AI) system. The MRAS model includes reference and adaptive models while the AI technique is used to reduce the error between them. The idea behind the Artificial Immunity technique came from the human body's ability to differentiate between antibody and antigen. In simple terms, when a body suffers from an attack, the immune system recognizes the attacker as either an antibody or antigen. In the case of an antigen, it produces the appropriate antibody $[29,30]$. Several applications of Artificial Immunity technique are found in the literature [31-33]. In [34], the fuzzy logic control is used to build a speed estimator. The main problem faced by this control approach is the initial error of the starting period leads to a large percentage of error on the rotor speed value.

In [35], two controllers for the DFIG are designed: the stator/grid-side controller (GSC) and the rotor-side controller (RSC). The adaptive neuro-fuzzy inference system is used instead of conventional PI and fuzzy controllers. The suggested approach shows large errors between actual and estimated 
values. In this paper, an AISE is used due to its robustness and reliability. To generate maximum power, the generator must operate at optimal tip-speed ratio [36]. Maximum Power Point Tracking (MPPT) algorithms can be classified into four control techniques. The first one is known as the Tip Speed Ratio (TSR) where the wind speed and the measured speed are used to regulate the rotor speed and capture the maximum wind power [37]. This method depends on the accuracy of the measured values obtained. The second technique is the Power Signal Feedback (PSF) which is based on the wind turbine maximum power curve. The curves are usually obtained via simulation or off-line experiment. Thus, it is difficult to implement this technique in practical applications [38]. The third technique is the Perturb and Observe ( $\mathrm{P} \& \mathrm{O}$ ) method. Mainly, it is used in solar energy where the measured currents and voltages are collected from the photovoltaic cell and processed through micro-controllers [16]. This technique is suitable for wind turbines with a small inertia, but not for medium and large inertia wind turbine systems, since the $\mathrm{P} \& \mathrm{O}$ method adds a delay to the system control [39]. Finally, the Optimum Torque Control (OTC) depends on the adjustment of the generator torque to the optimum value for various values of the wind speed [40]. This MPPT strategy needs a look-up table of optimum torques [41].

This paper introduces an AI MPPT algorithm which aims to surmount the disadvantages of the conventional MPPT algorithms. The proposed control strategy has been applied to a wind system driven by a DFIG which operates at variable speed. The stator is connected directly to the distributed grid and the rotor windings are connected via a Pulse Width Modulation (PWM) back-to-back converter. Even though the DFIG is considered as a stable symmetric induction machine, there might exist regions of instability due to the natural variation of the wind. The eigenvalue prediction for mapping the boundary of the stability region for DFIG machines was investigated by Banakar [42]. The analysis shows that the stability region of the DFIG machine can be defined by varying the $d, q$ and rotor current angle in the $i_{r d}-i_{r q}$ plane for sensorless rotor position estimation which is based on the model reference adaptive system (MARS) [43]. Although the aforementioned papers [44-46] explain the stability criterion for DFIG machines, the control scheme for stable operation remains unaddressed. The non-linear nature of the DFIG model motivated the authors to develop non-linear control design techniques that ensure a smooth and stable operation for the DFIG. There has been a lot of progress in the non-linear control designing context in the past years. Most of these control techniques have been used to control the DFIG [47-59]. Some of the latest studies are recalled. A non-linear control strategy to stabilize the DFIG based on back-stepping algorithm is proposed in [47]. The proposed controller is successful in tracking the reference rotor speed and in stabilizing the stator power. This control approach provides sufficient results, but it still suffers from a lot of constraints with respect to the designing procedure. In [48], a robust non-linear feedback control approach for a residential Savonuis Vertical Axis Wind Turbine (VAWT) with DFIG connected to a power grid is introduced. This work aims to control the Rotor Side Converter (RSC) using a robust non-linear feedback control scheme. In this work, a robust control law based on Lyapunov theory associated with a sliding mode controller is used to handle the issue of parameter uncertainty and to guarantee the global asymptotic stability of the system. The results of this approach are proven to be acceptable. The work is considered incomplete, because the obtained results do not show good robustness against parameter uncertainty. Another example of non-linear design technique is investigated in [52].

An input-state feedback linearization controller is proposed in this paper. A system of eight ordinary differential equations is used to model the wind energy conversion system. The generator has a wound rotor type with back-to-back three phase power converter bridges between its rotor and the grid. It is modeled using the direct-quadrature rotating reference frame with aligned stator flux. The mathematical model developed in this paper is an approximated model which makes the result of this controller not applicable in actual situations. Even though there have been several attempts to design the most powerful non-linear control technique, it is still an open area of research. In this paper, a control technique for controlling the DFIG and MPPT is developed. It is based on the asymptotic output tracking technique. The non-linear controller works on decoupling of the system parameters 
to facilitate the control of non-linear differential systems. In addition, it helps in applying direct digital control techniques while achieving asymptotic tracking. The control approach is based on the noninteracting control with tracking technique. The non-linear design approach is first introduced in [57].

By merely applying feedback with indeed assigned zeros, the system reproduces an output rotor current that converges to a specific reference signal. The reference signals of the direct and quadratic axis current components are generated from the artificial immunity controller. Different artificial intelligent MPPT techniques have utilized the FPGA. A review of different FPGA implementation for most efficient MPPT techniques is introduced. This review finds the benefits gained from FPGA implementation such as a high dynamic response, design flexibility and higher accuracy. The MPPT is targeted for maximizing the clean and eco-friendly electrical generation. As a result, the reduction in $\mathrm{CO}_{2}$ emission is also calculated.

The paper is structured as follows: Section 2 recalls the modeling of the Doubly Fed Induction Generator (DFIG) and the wind turbine models. Section 3 illustrates the overall control strategy applied in the DFIG. It is then followed by the illustration of asymptotic output. Section 4 illustrates the proposed control strategy based on Artificial Immunity AI technique. The design is analyzed with respect to wind speed variations. Finally, the simulation results are posed in Section 5.

\section{Wind Turbine and DFIG Modeling}

This section addresses the modeling of DFIG and wind turbine model, respectively. The DFIG model in the sequence reference frames is based on Stator Voltage Orientation (SVO).

\subsection{Doubly Fed Induction Generator Model}

To simplify the DFIG model, the following assumptions are made [58]:

1. The flow distribution is sinusoidal.

2. The air gap is constant.

3. The influences of the heating and the skin effect are not considered.

4. The saturation of the magnetic circuit is negligible.

The DFIG modeling with respect to a rotor flux oriented reference frame is expressed as follows. Equations (1)-(4) are utilized for stator representation while Equations (5)-(8) illustrate the rotor formulas.

$$
\begin{gathered}
V_{s d}=R_{s} i_{s d}+\frac{d}{d t} \lambda_{s d}-\lambda_{s q} W_{s} \\
V_{s q}=R_{s} i_{s q}+\frac{d}{d t} \lambda_{s q}+\lambda_{s d} W_{s} \\
\lambda_{s d}=L_{s} i_{s d}+M i_{r d} \\
\lambda_{s q}=L_{s} i_{s q}+M i_{r q} \\
V_{r d}=R_{r} i_{r d}+\frac{d}{d t} \lambda_{r d}-\lambda_{r q} W_{r} \\
V_{r q}=R_{r} i_{r q}+\frac{d}{d t} \lambda_{r q}+\lambda_{r d} W_{r} \\
\lambda_{r d}=L_{r} i_{r d}+M i_{s d} \\
\lambda_{r q}=L_{r} i_{r q}+M i_{s q}
\end{gathered}
$$

The dynamics of the mechanical part of the wind turbine are represented by:

$$
J \frac{d W}{d t}=c_{m}-c_{e}-c_{f} W
$$




$$
c_{e}=P \frac{M}{L s}\left(\lambda_{s q} i_{r d}-\lambda_{s d} i_{r q}\right)
$$

The system is now modeled with respect to the rotor side direct and quadratic $(d, q)$ synchronous reference frame. The input in such case are $i_{r d}$ and $i_{r q}$.

First, the system expression with respect to $d$-axis frame:

$$
\begin{gathered}
V_{r d}=R_{r} i_{r d}+L_{r} \Lambda i_{r d}-L_{r} \Lambda W_{r} i_{r q} \\
\dot{i_{r d}}=\frac{1}{L_{r} \Lambda} v_{r d}-\frac{1}{\Gamma \Lambda} i_{r d}+W_{r} i_{r q} \\
\Lambda=\left(1-\frac{M^{2}}{L_{s} L_{r}}\right) \\
\Gamma=\frac{L_{r}}{R_{r}}
\end{gathered}
$$

Now, consider $q$-axis frame:

$$
\begin{aligned}
& V_{r q}=R_{r} i_{r q}+L_{r} \Lambda \dot{i_{r q}}-L_{r} \Lambda W_{r} i_{r d} \\
& \dot{i_{r q}}=\frac{1}{L_{r} \Lambda} v_{r q}-\frac{1}{\Gamma \Lambda} i_{r q}-W_{r} i_{r d}
\end{aligned}
$$

Finally, we obtain the speed from the torque equation as:

$$
\dot{W}=-\frac{C f}{J} W-P \frac{M}{L_{s}}\left(\lambda_{s q} i_{r d}-\lambda_{s d} i_{r q}\right)
$$

\subsection{Wind Turbine Model}

For a given wind speed $v_{w}$, the mechanical power $P_{m}$ generated by the turbine is expressed as [40]:

$$
p_{m}=\frac{1}{2} \rho A c_{p}(\lambda, \beta) v_{w s}^{3}
$$

The tip speed ratio can be determined from $\lambda=\frac{\Omega_{r} s R}{v_{m}}$ where $\Omega_{r}$ represents the rotational speed of the wind turbine in rad/s. The optimal DFIG speed to achieve a maximum wind power tracking is given by:

$$
\Omega_{r}^{*}=\frac{\lambda_{o} p t v_{\hat{w} s}}{R}
$$

The power coefficient is a non-dimensional term modeled by the following equation:

$$
c_{p}=0.398 \sin \left(\frac{\pi(\lambda-3)}{15-0.3 \beta}\right)-0.0039(\lambda-2) \beta
$$

\section{DFIG Control Strategy}

The proposed technique only considers the control of the rotor side converter of the doubly-fed induction generator. The overall scheme of the RSC is shown in Figure 1. The control of the generator rotor speed $\Omega_{m}$ and the reactive power Qs is independently achieved utilizing current regulations. In Figure 1, there are two control loops. The outer control loop is realized using the Artificial Immunity System (AIS) technique which is detailed in Section 4. The outer loop controls the rotor speed and the stator reactive power which is used to generate the reference signal of the direct and quadratic current components. The inner loop controls the direct and quadratic rotor axis currents. The non-linear ASymptotic Output (ASO) tracking technique is applied in the inner loop. The control is realized in the rotor reference frame, so the $d$-axis regulates the reactive power and the $q$-axis governs the 
active power. In general, the system produces an output regardless of the initial state of the system which converges asymptotically to the rotor reference current signal. The asymptotic output tracking technique is illustrated below in this section. The vector control strategy with stator field orientation is used to ensure decoupability of power control such that the generator speed and reactive power are, respectively, proportional to the rotor direct and quadratic currents.

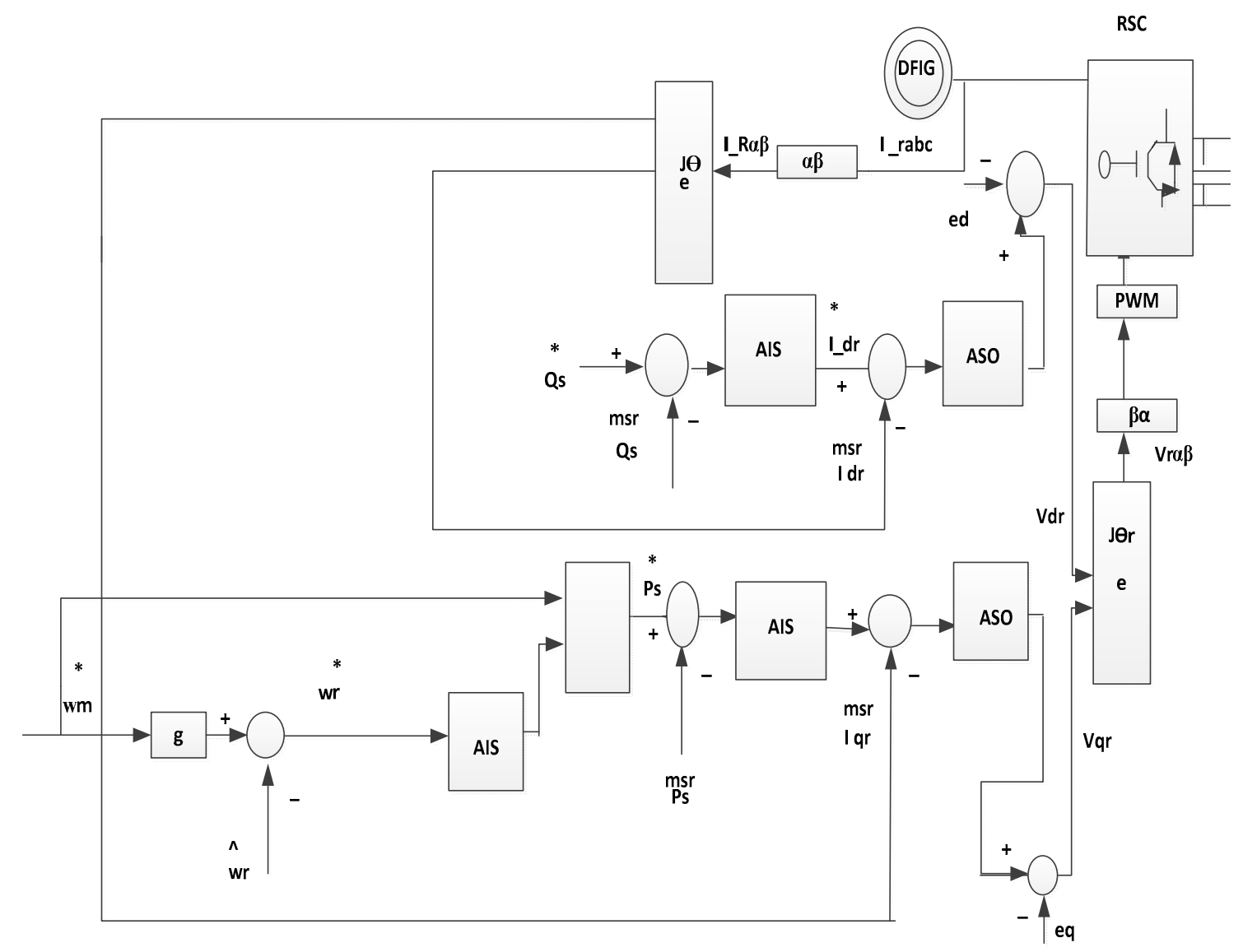

Figure 1. The Rotor Side Converter overall control scheme.

First, the system is modeled in the standard non-linear form. Recalling from the modeling section, the system is introduced in the condensed non-linear form [60].

$$
\Sigma_{C}:\left\{\begin{array}{l}
\dot{x}=f(x)+g_{1}(x) u_{1}+g_{2}(x) u_{2}, \quad x \in \mathbb{R}^{n}, u \in \mathbb{R}^{n} \\
y=h(x)
\end{array}\right.
$$

where $x=\left[\begin{array}{lll}x_{1} & x_{2} & x_{3}\end{array}\right]^{\mathrm{T}}=\left[\begin{array}{lll}i_{r d} & i_{r q} & w\end{array}\right]^{\mathrm{T}}, u=\left[\begin{array}{ll}u_{1} & u_{2}\end{array}\right]^{\mathrm{T}}=\left[\begin{array}{ll}v_{r d} & v_{r q}\end{array}\right]^{\mathrm{T}}$. The function $f(x) ; g(x)$ is smooth vector fields and the output function $h(x)$ is a smooth scalar function.

$$
\begin{gathered}
f(x)=\left(\begin{array}{c}
-\frac{1}{\Gamma \Lambda} x_{1}+x_{2} x_{3} \\
-\frac{1}{\Gamma \Lambda} x_{2}-x_{2} x_{3} \\
-\frac{C f}{J} x_{3}-P \frac{M}{L_{s}}\left(\lambda_{s q} x_{1}-\lambda_{s d} x_{2}\right)
\end{array}\right) \\
g_{1}(x)=\left(\begin{array}{c}
\frac{1}{\Gamma \Lambda} \\
0 \\
0
\end{array}\right), g_{2}(x)=\left(\begin{array}{c}
0 \\
1 \\
\Gamma \Lambda \\
0
\end{array}\right), h(x)=\left(\begin{array}{c}
i_{r d} \\
i_{r q}
\end{array}\right)
\end{gathered}
$$


Remark 1. According to the previous results obtained by Isidori [60], a multi variable non-linear system in the form of Equation (23) has a relative degree $r_{1}, \ldots, r_{m}$ at point $x^{0}$ if $L_{g j} L_{f}^{k} h_{i}(x)=0$ for all $1 \leq j \leq m$, for all $1 \leq i \leq m$, for all $k \leq r_{i}-1$, and for all neighbours of $x^{0}$.

The system has a well-defined vector relative degree $r=2$. The relative degree with respect to the first and the second input are $r_{1}=1$ and $r_{2}=1$, respectively.

The lie derivative of the output function:

$$
\begin{aligned}
& L_{g 1} h_{1}=\frac{1}{\Gamma \Lambda}, \quad L_{g 2} h_{1}=0 \\
& L_{g 1} h_{2}=0, \quad L_{g 2} h_{2}=\frac{1}{\Gamma \Lambda}
\end{aligned}
$$

Since the relative degrees are $r_{1}=1$ and $r_{2}=1$, the decoupling matrix takes the form:

$$
A=\left(\begin{array}{ll}
L_{g 1} L_{f}^{r_{1}-1} h_{1}(x) & L_{g 2} L_{f}^{r_{2}-1} h_{1}(x) \\
L_{g 1} L_{f}^{r_{1}-1} h_{2}(x) & L_{g 2} L_{f}^{r_{2}-1} h_{2}(x)
\end{array}\right)=\left(\begin{array}{cc}
\frac{1}{\Gamma \Lambda} & 0 \\
0 & \frac{1}{\Gamma \Lambda}
\end{array}\right)=\frac{1}{\Gamma \Lambda} I
$$

From the non-interacting control theory, if the decoupling matrix is nonsingular, then there exists a static feedback control law in the form of:

$$
u=\alpha(x)+\beta(x) w
$$

that solves the problem with:

$$
\alpha(x)=-A^{-1}(x)\left(\begin{array}{c}
L_{f}^{r_{1}} h_{1}(x) \\
L_{f}^{r_{2}} h_{2}(x)
\end{array}\right)=\left(\begin{array}{c}
x_{1}-\Gamma \Lambda x_{2} x_{3} \\
x_{2}+\Gamma \Lambda x_{2} x_{3}
\end{array}\right)
$$

and

$$
\beta(x)=A^{-1}(x)=\frac{1}{\Gamma \Lambda} I
$$

The imposition of the feedback yields a system characterized by:

$$
\begin{gathered}
z_{j, 1}=z_{1,2} \\
z_{j, 2}=w_{j} \\
\dot{\eta_{1}}=q(z,)+p(z, \eta) w \\
y_{j}=z_{j, 1} j=1,2
\end{gathered}
$$

Remark 2. The zero dynamics of the system in Equation (30) are described by:

$$
\dot{\eta}=q(0, \eta)-p(0, \eta) A^{-1}(0, \eta) \alpha(x)=\frac{C f}{J} x_{3}
$$

which can verify that the system is exponentially globally stable. Choosing the external control in the form:

$$
w=\left(\begin{array}{c}
w_{1} \\
w_{2}
\end{array}\right)=\left(\begin{array}{l}
-k_{1,2} z_{1,1} \\
-k_{2,2} z_{2,1}
\end{array}\right)
$$

to obtain the dynamics:

$$
\begin{gathered}
z_{1,1}=z_{1,2} \\
z_{j, 2}=w_{j}, j=1,2
\end{gathered}
$$


This property ensures the asymptotic output tracking of the required output behavior.

\section{AI MPPT Algorithm}

This section is dedicated to illustrating the novel of Artificial Immunity technique maximum tracking technique.

\subsection{Wind Speed Estimation}

The traditional way of calculating the wind speed can be carried out using the data of wind turbine power, tip speed ratio and the pitch angle. A lookup table can be used to implement the inverse function. Nevertheless, this method requires much memory space beside the calculation of the real time non-linear function roots may result in a complex and time consuming calculation. A solution for this problem is to use Artificial Intelligent techniques; in particular, Artificial Immunity (AI) technique is known to be a powerful tool due to its robustness and reliability. In this paper, a wind estimation method based on artificial immunity technique is introduced. The method approximates the non-linear inverse of Equation (24), as shown in Figure 2. First, the turbine mechanical power is calculated from the estimated DFIG speed given by AISE, which is presented in Section 4.2. The reference electromagnetic torque of the DFIG is determined from the rotor speed controller shown in Figure 1 and by considering power losses in the gearbox:

$$
\begin{gathered}
\Omega_{m}^{*}=g \Omega_{r}^{*} \\
\hat{P}_{m}=c_{e}^{r e f} \hat{\Omega_{m}}+P_{\text {loss }, g B}
\end{gathered}
$$

\subsection{Rotor Speed Estimation of the DFIG}

The proposed AISE observer consists of adaptive model and a reference model (MARS) in the closed loop scheme with an AIS. The AIS is used to reduce the error between the two models and provide the appropriate estimated rotor speed. The concept of Colona selection is used to build the AI technique. The Colona System Pattern is based on the idea of the differentiation between antigen (Ag) and antibody (Abs) where the (Ag) represents the problem to be solved, while the antibodies (Abs) are the candidate solutions of the problem. In our case, the estimated speed poses the problem Ag and the stored case scenarios are the Abs. The algorithm performs the selection of antibodies based on affinity either by matching against an antigen pattern or by evaluating the pattern via objective functions. The data used to train the system are based on the fuzzy technique applied in [40]. The overall and detailed AISE is shown in Figures 2 and 3, respectively, while the Artificial Immunity technique concept is shown in Figure 4. The Colona System Pattern explains the immune response when a given antibody recognizes an antigenic pattern. In the clonal selection algorithm, the antigen $(\mathrm{Ag})$ represents the problem to be optimized and its constraints, while the antibodies (Abs) are the candidate solutions of the problem. The antibody-antigen affinity indicates the matching between the answer and the challenge. The algorithm performs the selection of antibodies based on matching against an antigen pattern. The reference model is referred to in Section 2. To achieve a power decoupling control, the vector control strategy is adopted with a stator field orientation on the $d$-axis. Consequently, when $\lambda s q=0$, the $q$-axis rotor current can be rewritten as the function of the stator current:

$$
i_{r q}=\frac{L_{s}}{M} i_{s q}
$$

The estimated rotor voltage used to build the adaptive model is defined as:

$$
\hat{v}_{r q}=-\frac{R_{r} L_{s}}{M} i_{s q}+\left(M-\frac{L_{s} L_{r}}{M}\right) \frac{d i_{s q}}{d t}+\hat{W}_{s}\left(\left(\frac{L_{r}}{M} \lambda_{s d}\right)+\left(M-\frac{L_{s} L_{r}}{M} i_{s d}\right)\right)
$$




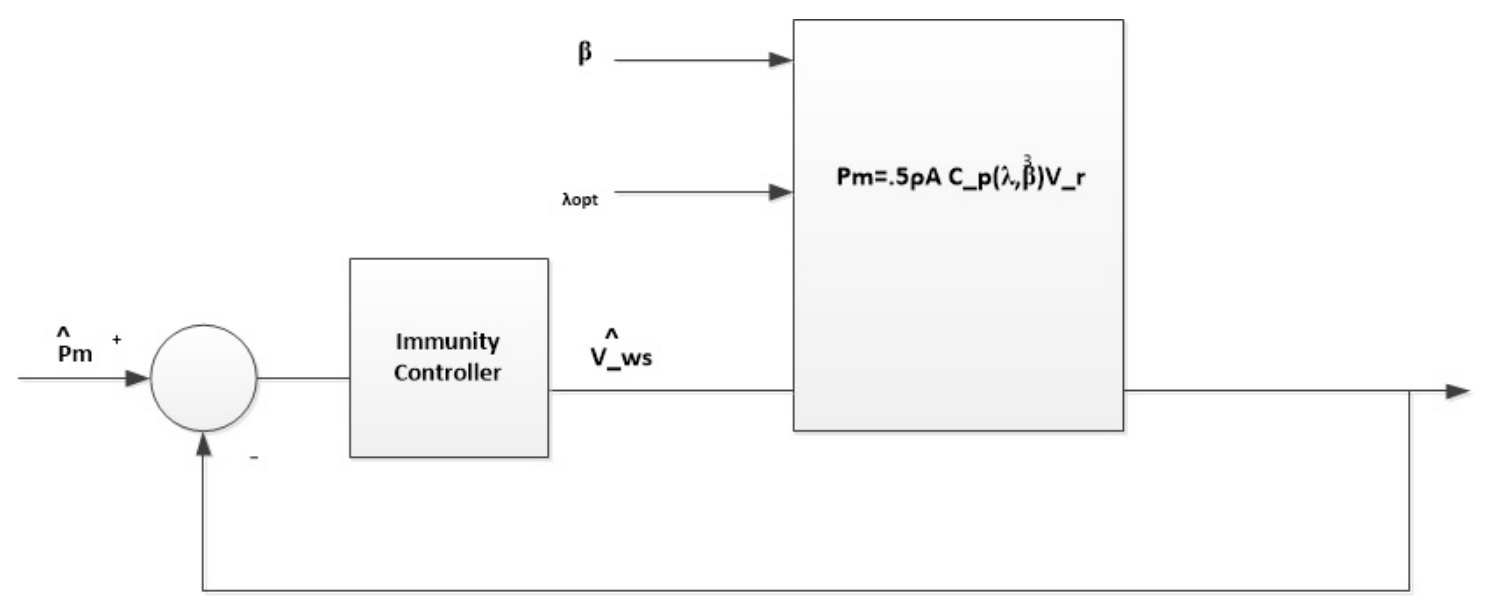

Figure 2. An artificial immunity technique based wind speed estimation.

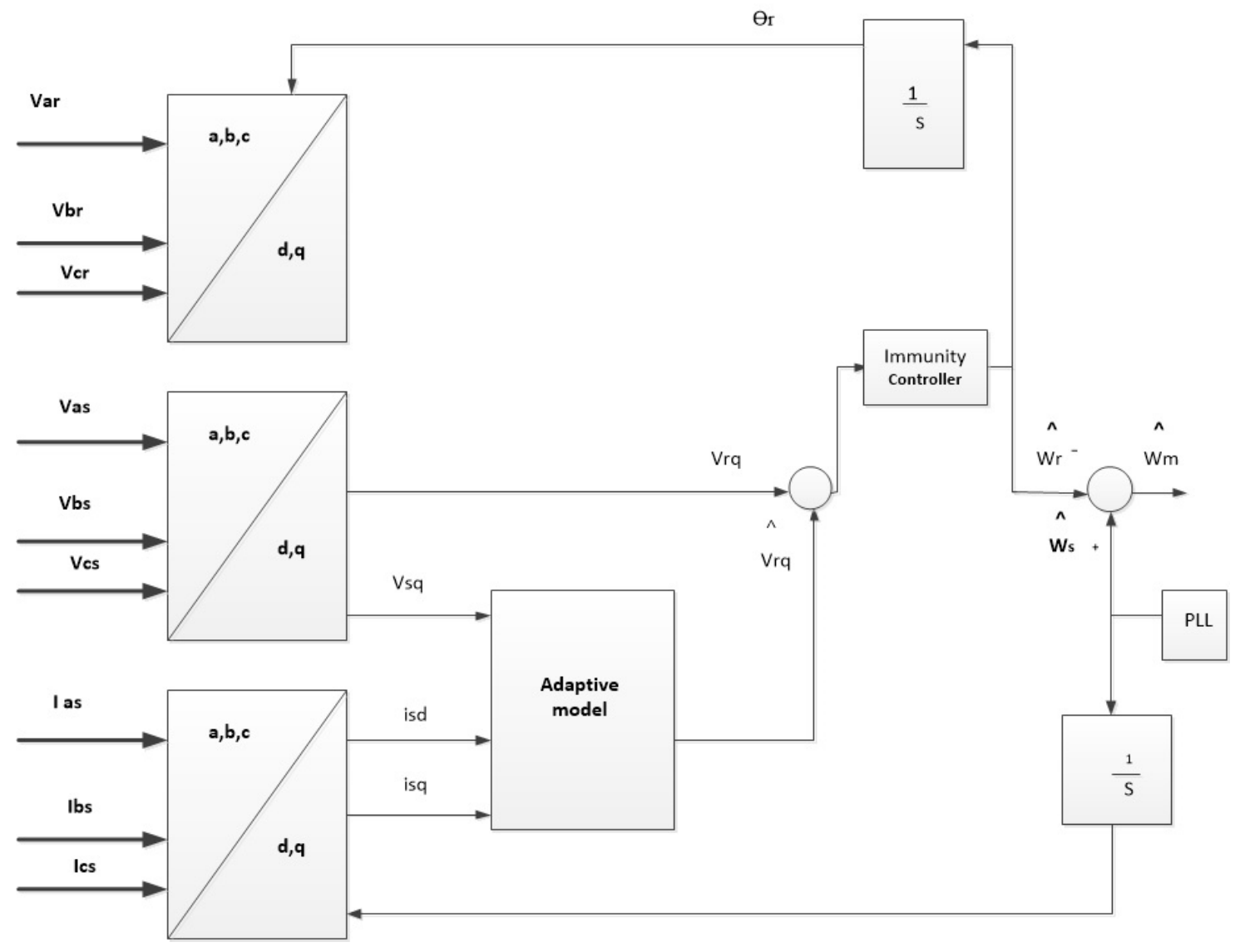

Figure 3. Detailed model of artificial immunity technique based wind speed estimation. 
Trained Data

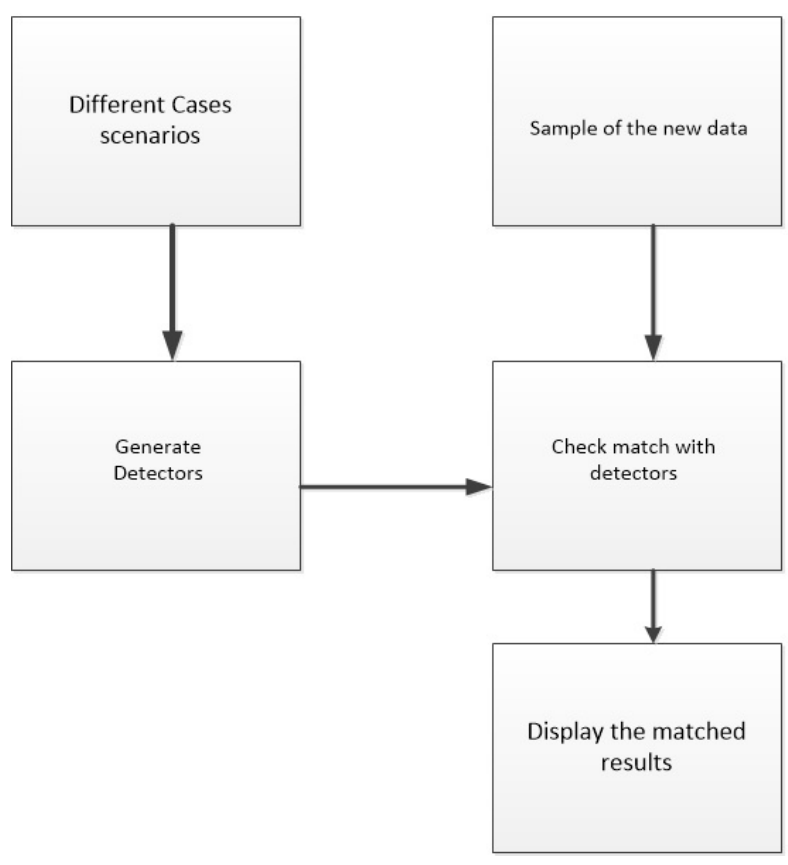

Figure 4. Block diagram of artificial immunity technique.

In this paper, MRAS observer based Artificial Immunity system is used to estimate the rotational speed of the DFIG. After estimating the rotor electrical angular velocity, the rotational speed of DFIG is estimated using the electrical frequency through phase-locked loop (PLL).

\subsection{Sensorless MPPT Proposed Technique}

A sensorless MPPT solution based on the Artificial Immunity technique is introduced. The estimation of the overall power losses in the wind turbine generator and the estimated wind speed, shown in Figure 5, are used to provide the optimal value of power coefficient. The structure of AI MPPT is illustrated in Figure 6. The data used to train the system are provided from artificial fuzzy technique [40]. The idea in a simple term is that the system collects the input data and deals with it as an antigen. The data are then compared to the different scenarios when a match is detected, and then the value of MPPT is determined. The main advantage of this sensorless AI MPPT is that it reduces the size of PWM back-to-back converter while tracks the maximum power point which reduces the overall system costs. First, for the adopted MPPT algorithm, the optimal value of the power coefficient by taking into account the power losses is expressed as:

$$
c_{p}^{o p t}=\frac{P_{\text {losses }}+P_{\text {rated }}}{2 \rho A \hat{v}_{w s}^{3}}
$$

The optimal value of the power coefficient is provided through the calculation of optimal ratio $\lambda_{\text {opt }}$. The mathematical representation of the $c_{p}$ curves is given by Equation (20), while the optimal generator reference speed $W_{r}$ for maximum wind power tracking is determined from Equation (19). The AI MPPT controller was programmed in $C$ code using an embedded MATLAB function in MATLAB R2016a SIMULINK software (The MathWorks, Inc., Natick, MA, USA). 


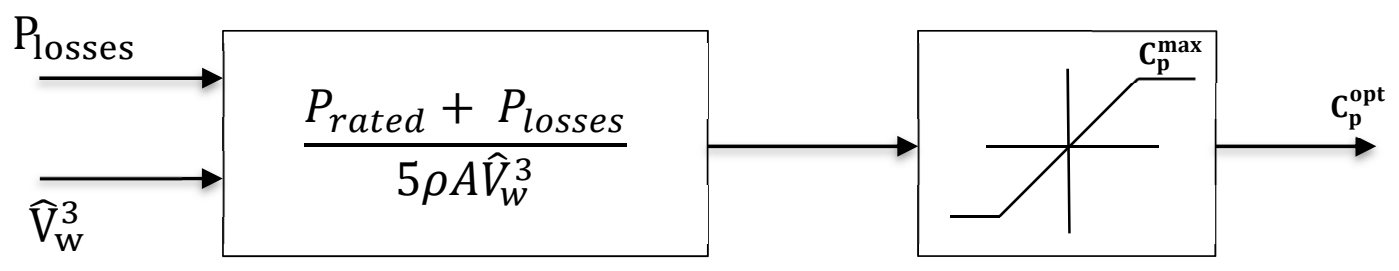

Figure 5. Calculation of optimal power coefficient.

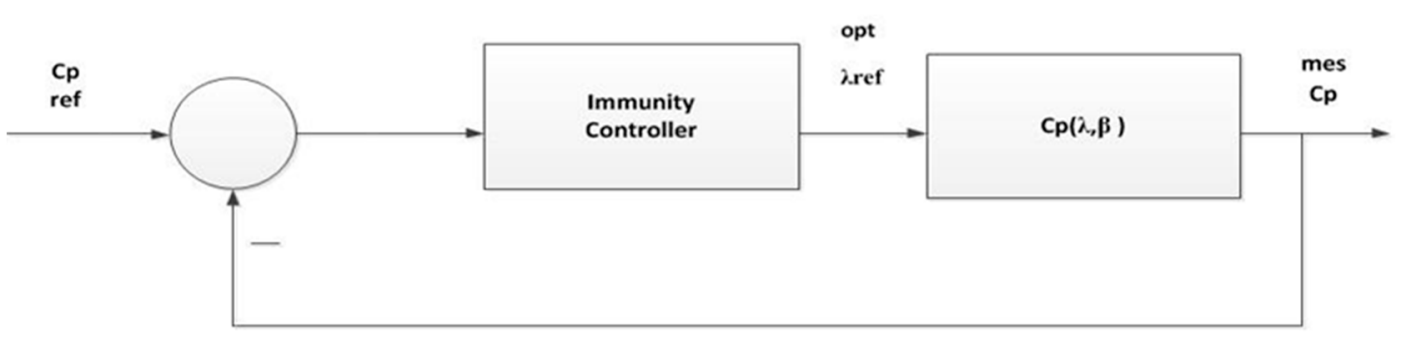

Figure 6. Structure of the Artificial Intelligent Eco-MPPT.

\section{FPGA Based Implementation for MPPT Techniques}

MPPT techniques based on artificial intelligence are very common to get an accurate and better performance of solar/wind systems. Managing many data and high computing power are very crucial for these techniques. Different hardware platforms can be utilized for this purpose such as graphics processing units (GPU), general purpose processors (GPGPU) and field programmable gate arrays (FPGA). Even though a GPU has many computational cores, FPGA has more advantages. It has better performance per watt and also provides flexible reconfigurable hardware [61]. FPGA is an integrated circuit which is configured using Very high speed integrated circuits Hardware Description Language (VHDL) or Verilog. Many studies consider the FPGA implementation of MPPT.

Implementing different artificial intelligence MPPT techniques on FPGA are studied in [62]. The main methods considered were neural network (NN), fuzzy logic controller (FLC), genetic algorithm (GA), and hybrid systems such as adaptive neuro-fuzzy inference systems (ANFIS). All these methods with a complete PV system were simulated using Simulink from MATLAB. Finally, a real time co-simulation based on Vertix V FPGA from Xilinx was performed for the best controller, FL-GA, to figure out the performance of the whole system in real time. The authors provided a fast system prototype implementation and evaluation by exploiting the Xilinx's system generator from Mathworks Simulink which allows MATLAB to program the Xilinx chip. The simulation showed that the total look up tables (LUTs) utilized were varied from $1 \%$ for ANFIS to $17 \%$ for NN. The total logic elements used were varied from $1 \%$ for ANFIS to $13 \%$ for optimal FLC. All Algorithms utilized 4\% I/O ports from the target chip. The total power consumption was less than $0.5 \mathrm{~W}$.

In [63], authors also analyzed most common MPPT techniques. The main methods discussed were neural networks (NN), FLC, genetic algorithms (GA), particle swarm optimization (PSO), and ant colony optimization technique. The authors preferred to implement these techniques on FPGA rather than microcontroller or digital signal processing (DSP) platforms due to the memory space provided and its ability to be reconfigurable. Moreover, lower cost implementation was another advantage as the FPGA can integrate all functions on the same chip and perform all computations rather than DSP which executes only the computation related to DSP. Lower power consumption, higher performance, and higher hardware resources such as memory required were afforded by utilized FPGA. 
Different perturb and observe method maximum power point tracking techniques (P\&O MPPT) are reviewed in [64]. The assessment of these techniques were based on complexity, total system cost, accuracy, convergence speed and hardware requirements. These studies show that artificial neural network (ANN), fuzzy logic controller (FLC) method, and PSO method give best tracking accuracy. Implementing these techniques on FPGA affords a good dynamic performance, high flexibility, less quantization error and easiness integration with the whole system. Moreover, FPGA affords a low cost to function ratio when comparing to other controllers such as digital signal processing (DSP) platform.

Bat algorithm based maximum power point tracking (BAMPPT) for PV system was introduced in [65]. Bat algorithm is one of the swarm intelligence based methods. The proposed controller is a reconfigurable module as it was designed by a VHDL code. The proposed algorithm was configured on Xilinx Virtex-5 (XC5VLX50-1FFG676) FPGA for real time verification. The FPGA hardware platform outperforms the DSP platform as it can perform more one operation in one clock cycle due to its parallelism architecture. Despite the complexity of the algorithm, FPGA provides a low latency of computing time and better resolution which improves the performance of the controller.

In [66] a low cost cyclone III FPGA was utilized to implement a fast and compact virtual anemometer which was depend on growing neural gas (GNG ANN) with 512 neurons. The proposed virtual anemometer was utilized for WECS which perform the MPPT in a noniterative technique. In the proposed system the controller composed of a microcontroller that send the main data about the machine, angular speed and torque, to the FPGA which performs the MPPT technique. The proposed system utilized 90\% logic elements, 9.1\% registers and 24.2\% 9-bit embedded multipliers from the whole chip. The proposed system was suggested for embedded applications with up to $100 \mathrm{kHz}$ bandwidth for WECS control.

In [67], a FLC MPPT is implemented on FPGA in a photovoltaic system (PV). The proposed system composed of PV panels, boost converter, current and voltage sensing circuit and the FPGA controller. The proposed FLC MPPT controller generates width modulated pulses which play as a clock signal for boost converter. This controller is reconfigurable as it can be simply changed by modifying the parameters of the VHDL code and hence offers a high flexibility and upgradability for the design. Moreover, the proposed design provides a low cost implementation as all electronic components required for the controller are integrated in the same FPGA chip. Low power consumption and fast response are also advantages of using the FPGA hardware platform.

Figure 7 shows the functional block diagram for the proposed control system which can be implemented on FPGA hardware platform. This architecture is composed of four main blocks. The first one calculates $\hat{P}_{m}$ which is one of the inputs of the second main module. To reduce the required hardware area, the $v_{q}$ and $v_{d}$ values are calculated as the area is the second main module. All data required to calculate $v_{q}$ and $v_{d}$ values are stored in Data_measure_memory module. The last main module is the control unit which controls the outputs of Data_measure_memory module to allow later calculating $v_{q}$ or $v_{d}$. 


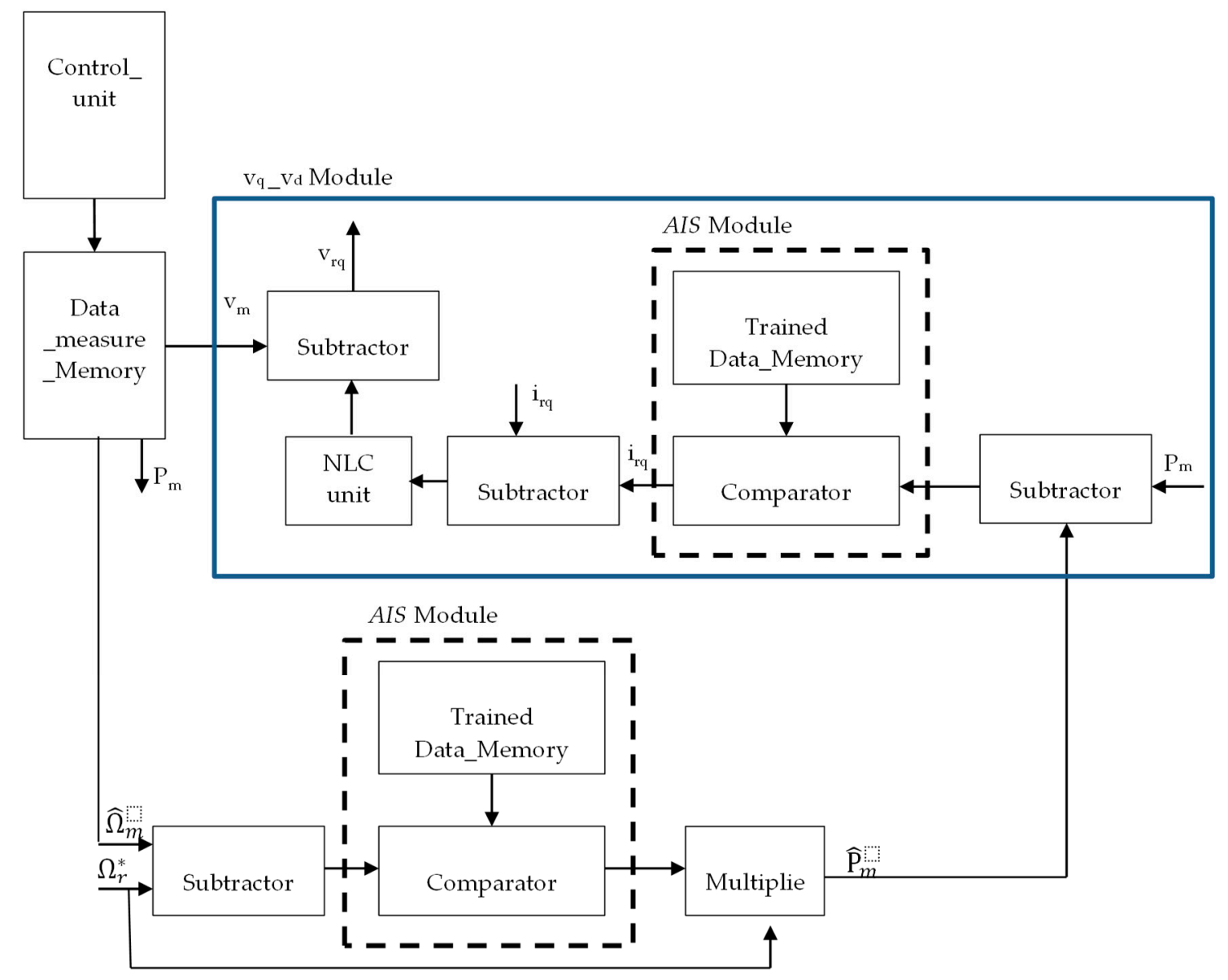

Figure 7. Proposed FPGA hardware implementation of proposed controller system.

\section{Simulation and Results}

This section is dedicated to evaluating the performance of the proposed technique. The introduced approach method was applied to a wind turbine generator driving $3.7 \mathrm{~kW}$. MATLAB was used to emulate the wind variation and to compare the proposed AI MPPT with the conventional and fuzzy logic methods. It was also used to test the performance of the non-linear input-output decoupling with asymptotic tracking technique. The parameter used to evaluate the performance and the effectiveness of the proposed technique are shown in Table 1. The measured and estimated wind speed are shown in Figure 8. The performance of the AISE is shown in Figure 9. It can be noticed that the tracking error is less than 3\%. The DFIG rotor speed estimation is illustrated in Figures 10 and 11, where the direct and quadratic rotor current of DFIG is shown in Figure 11, while the direct and quadratic rotor voltage is shown in Figure 10. To evaluate the ability of control design to track the direct and quadratic rotor currents reference signal generated from the AIS controller (Figure 11), an input in the form $u=\alpha(x)+\beta(x)$ is used. In Figure 12, the proposed control technique succeeded in reproducing a current signal that coincides with the required reference signal in both cases. Figure 13 illustrates the wind speed behavior at the different time (i.e., usually called wind speed profile). To analyze the effectiveness of the proposed controller, a classical PID control is applied and simulated via MATLAB using the same parameters. Figure 14 depicts the Maximum Power Point Tracking curves conducted from classical PID controller and new AI MPPT. The results indicate that the proposed controller provides better performance as it shows a slower dynamic variation of the rotor speed compared to the PID controller. The system behaviors, which are illustrated in Figures 7-15, are detected versus time (in seconds). 
Moreover, the performance of the proposed technique was compared to the Fuzzy logic controller introduced in [40]. The fuzzy log model was also built on MATLAB based on the data found in [40]. The results shown in Figure 15 prove that the AI MPPT provide a better performance than both the Fuzzy Logic Controller and the classical ones. The size of the power converter is reduced as the slip which is directly proportional to the converter is reduced as shown in Figure 16. Consequently, the size of the power converters can be downsized without lowering the output power which leads to the reduction in both the cost and maintenance of the overall system by reducing the size of the back-to-back converters. Figure 16 shows the comparison of the optimal tip speed ratio of both MPPT strategies. The execution time generated from all techniques is illustrated in Table 2. Even though the execution times of the fuzzy controller and classical methods are less than the AIS, the reduction in the speed variation makes it worthwhile. On the other hand, the results generated from AIS regarding tracking MPPT proved to be smoother and more reliable.

Table 1. The DFIG data sheet.

\begin{tabular}{cc}
\hline The DFIG Data $\mathbf{0 . 2} \mathbf{~ m H}$ of a Typical $3.7 \mathbf{~ k W}$ Generator \\
\hline Frame/power & $3.7 \mathrm{~kW}$ \\
Efficiency at rated speed & approximately $97-97.5$ \\
Voltage & approximately $1000 \mathrm{~V}$ \\
Locked rotor voltage & $1000-2000 \mathrm{rpm}$ \\
Operation speed range & p.f. $0.90 \mathrm{cap}-1.0$ \\
Power factor & $1 \mathrm{~kW}$ \\
Rotor Resistance & $0.5 \mathrm{~kW}$ \\
Rotor Inductance & $0.001 \mathrm{mH}$ \\
Stator Resistance & $M_{s r}=0.078 \mathrm{H}$ \\
Stator Inductance & 4 \\
Mutual inductance & $J=0.3125 \mathrm{Nms}^{2}$ \\
Number of poles & \\
Inertia moment &
\end{tabular}

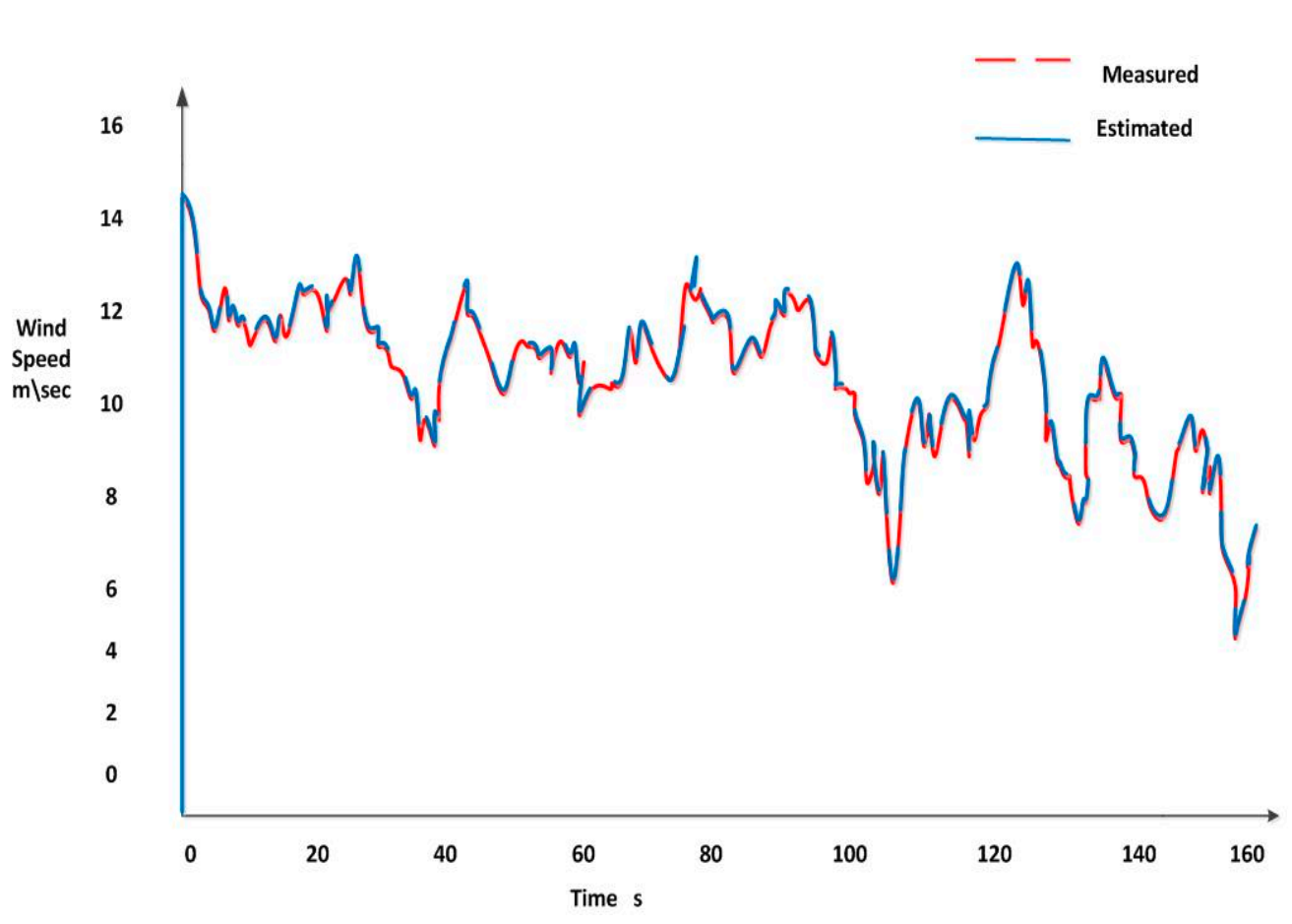

Figure 8. The wind speed estimated curve. 


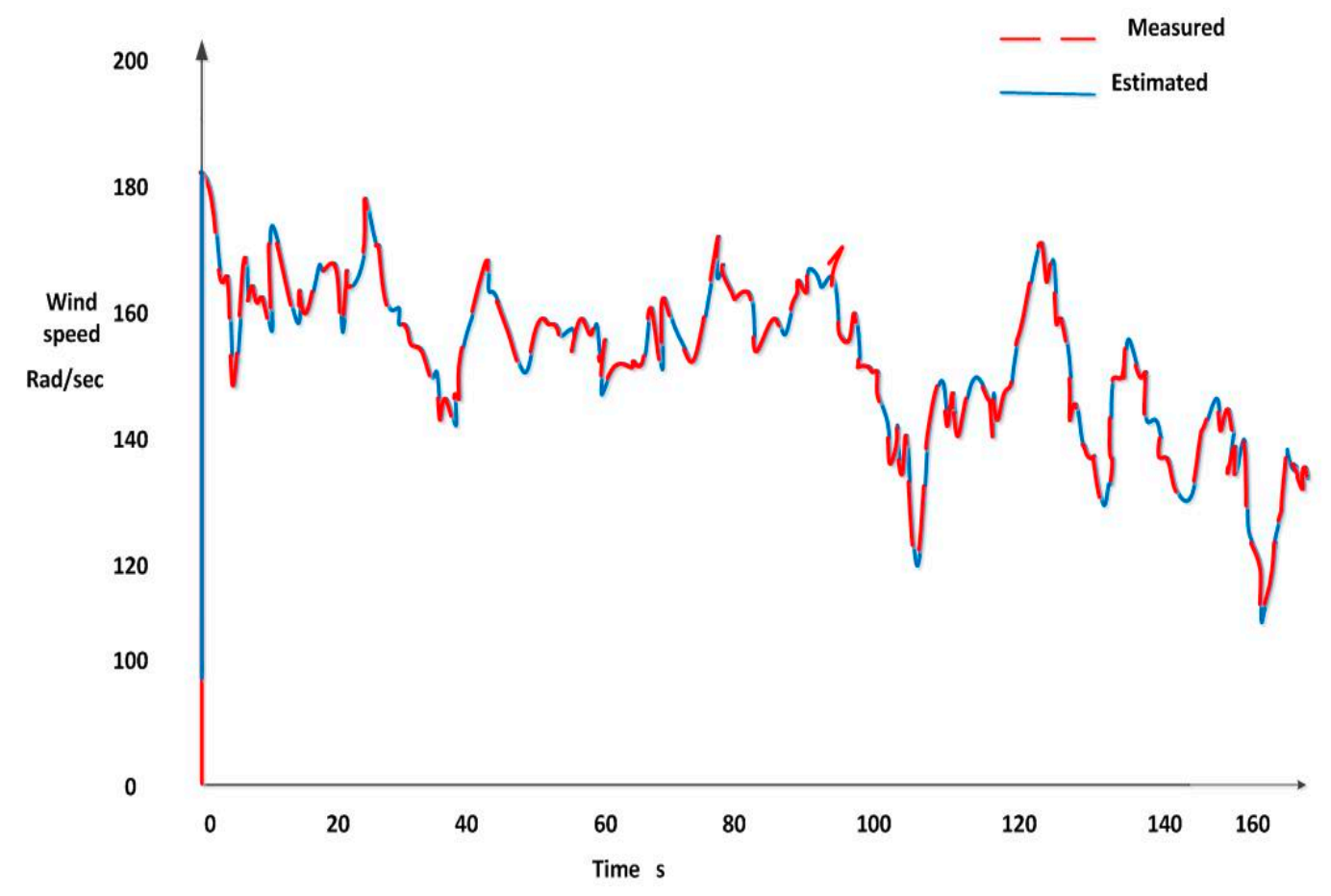

Figure 9. DFIG rotor speed estimation performance using AISE.
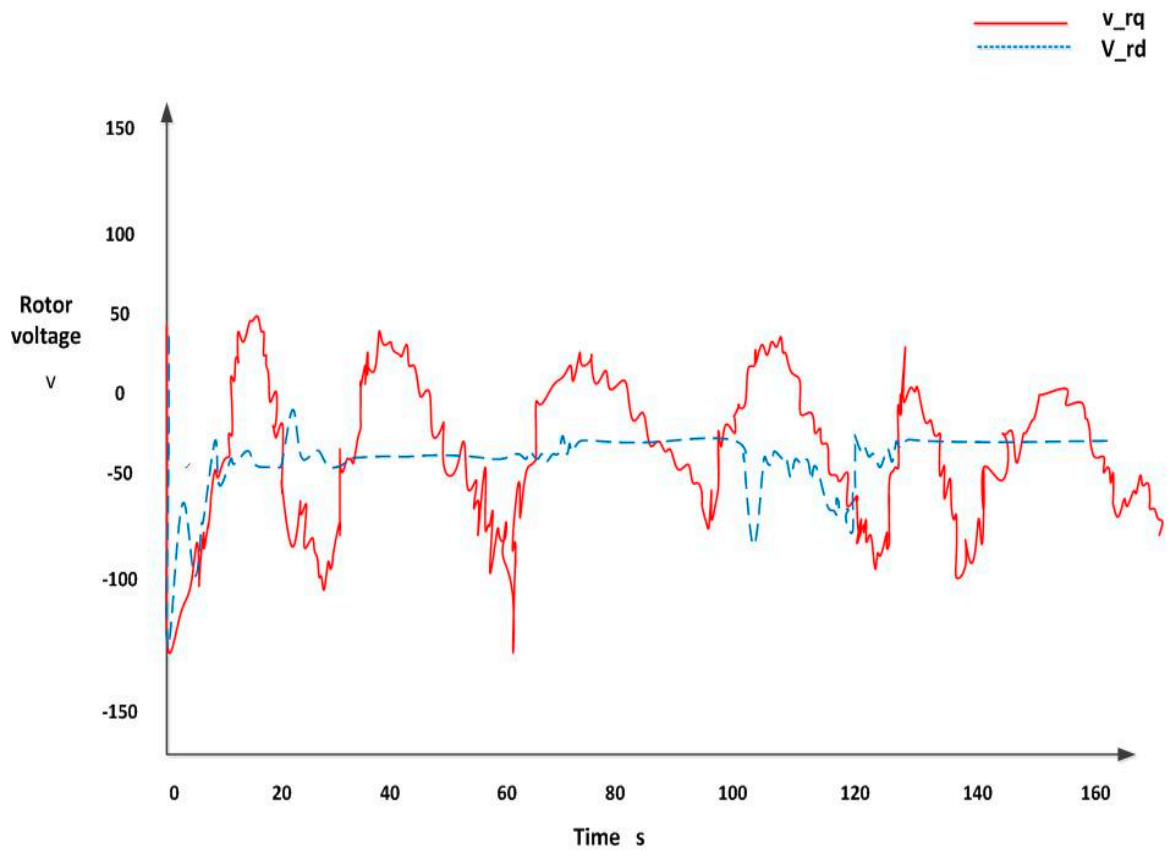

Figure 10. The DFIG rotor quadrature and direct voltages $\left(V_{r q}\right.$ and $\left.V_{r d}\right)$. 


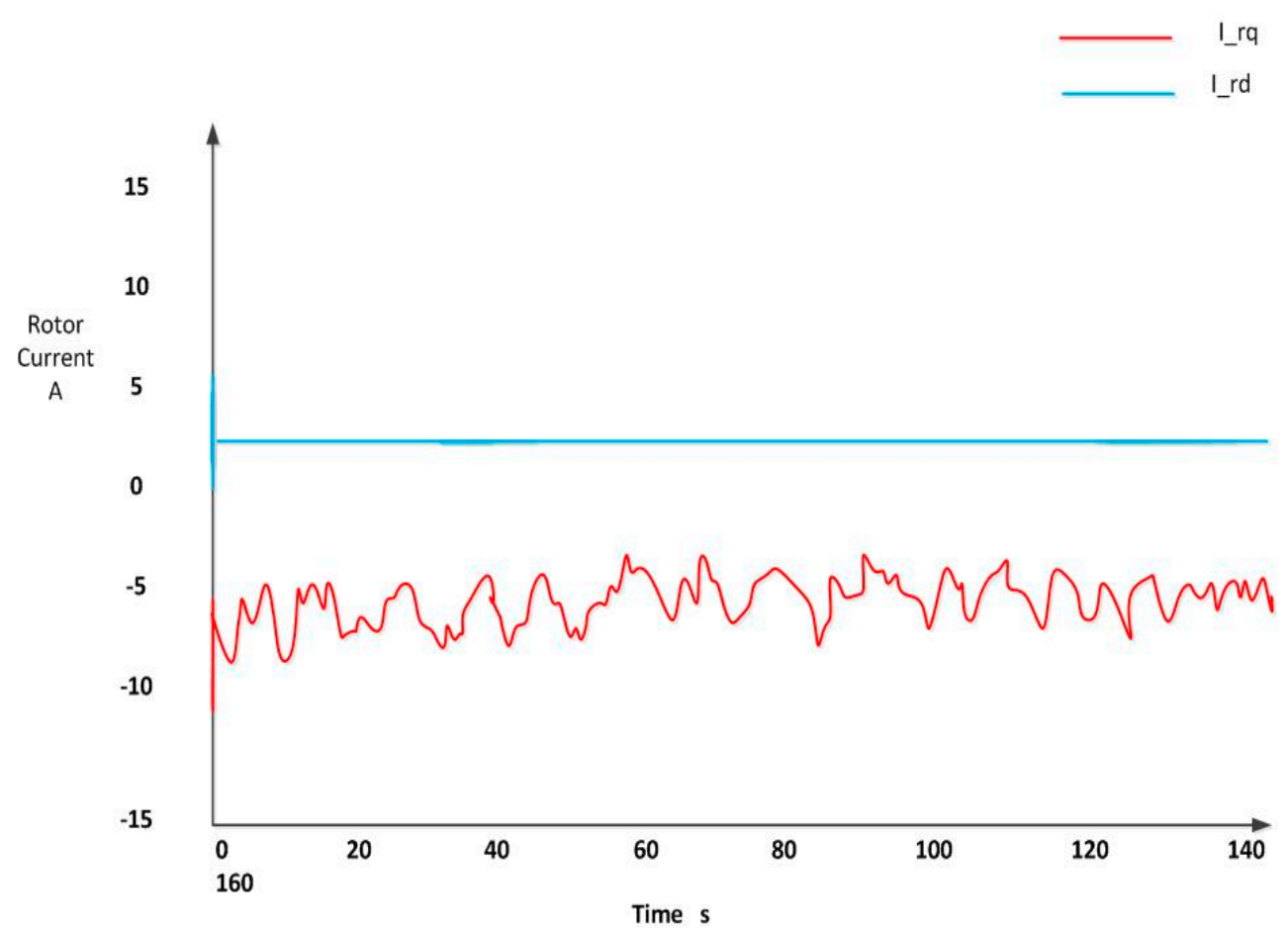

Figure 11. The DFIG rotor quadrature and direct current curves $\left(I_{r q}\right.$ and $\left.I_{r d}\right)$.

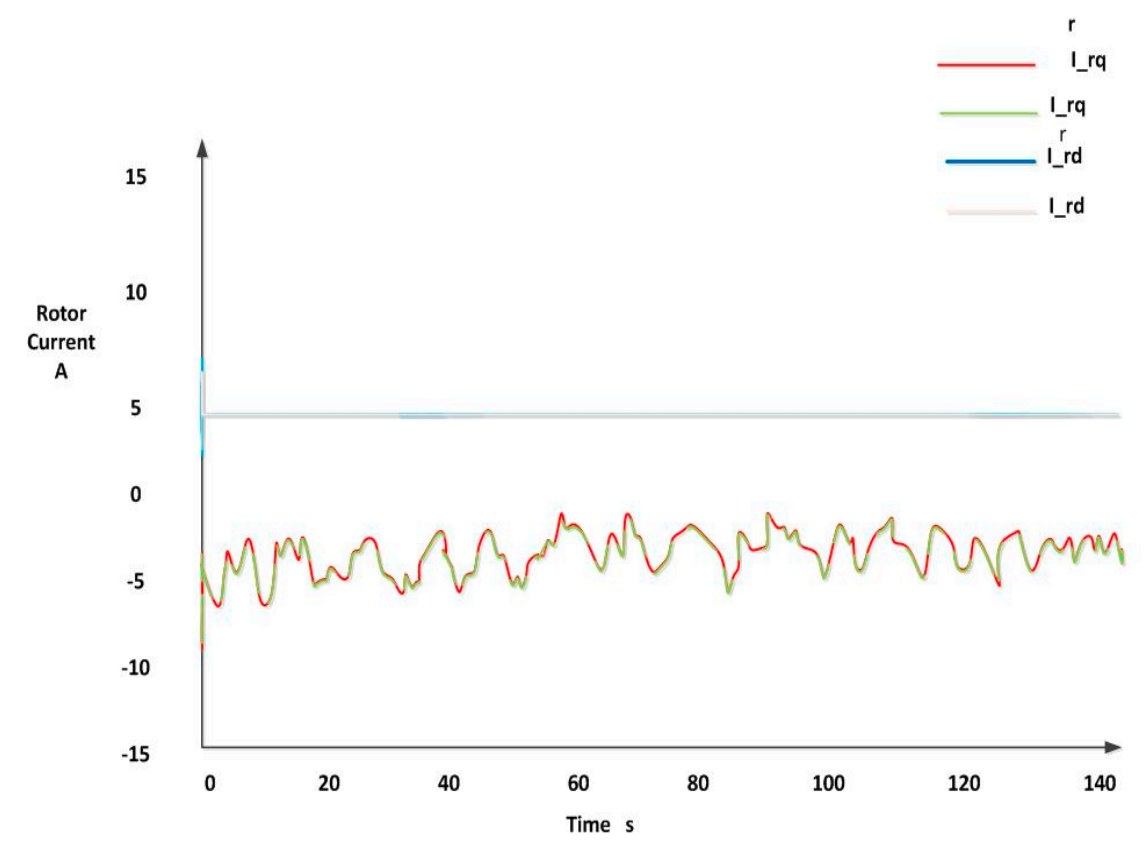

Figure 12. Non-linear control tracking rotor quadrature and direct currents and their references. 


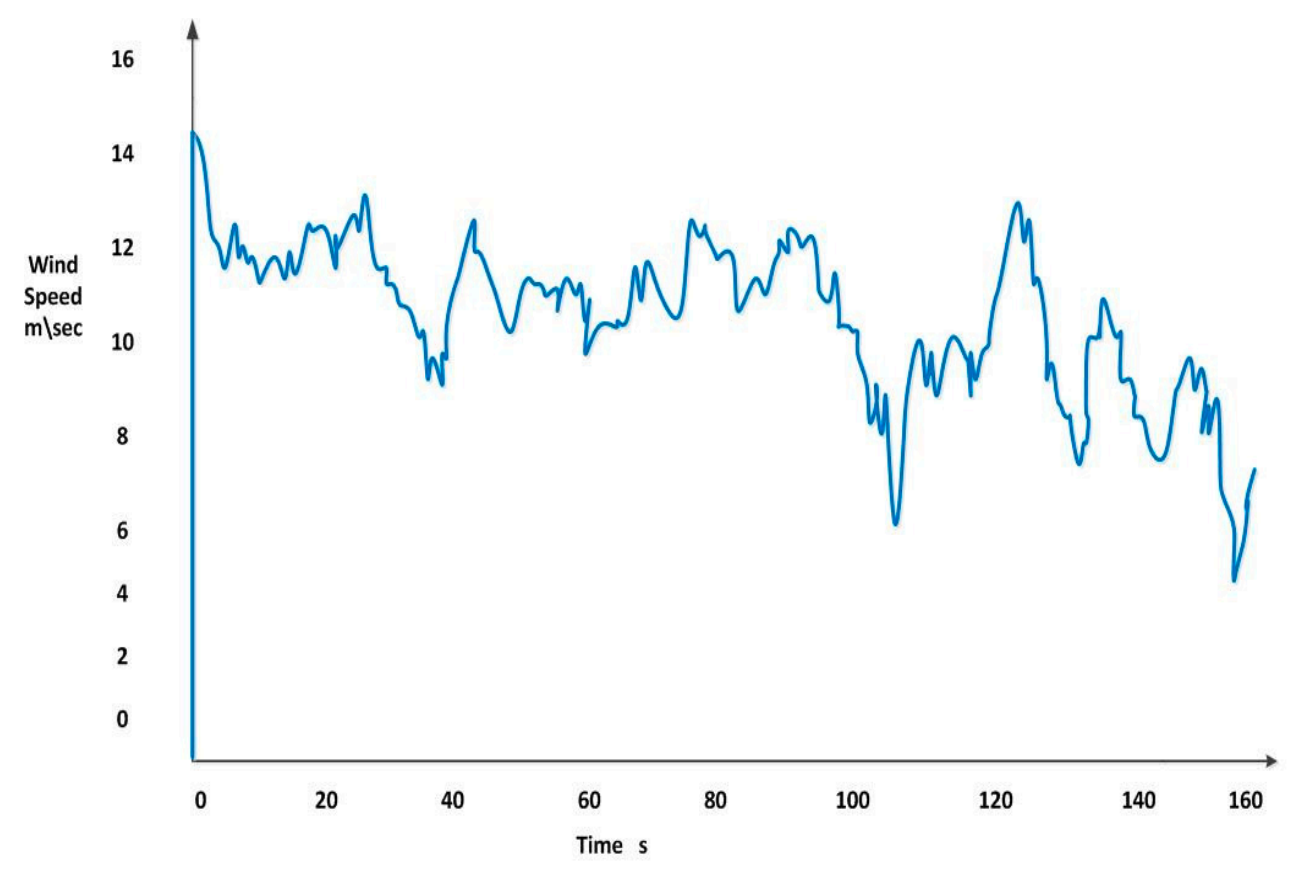

Figure 13. The wind speed profile.

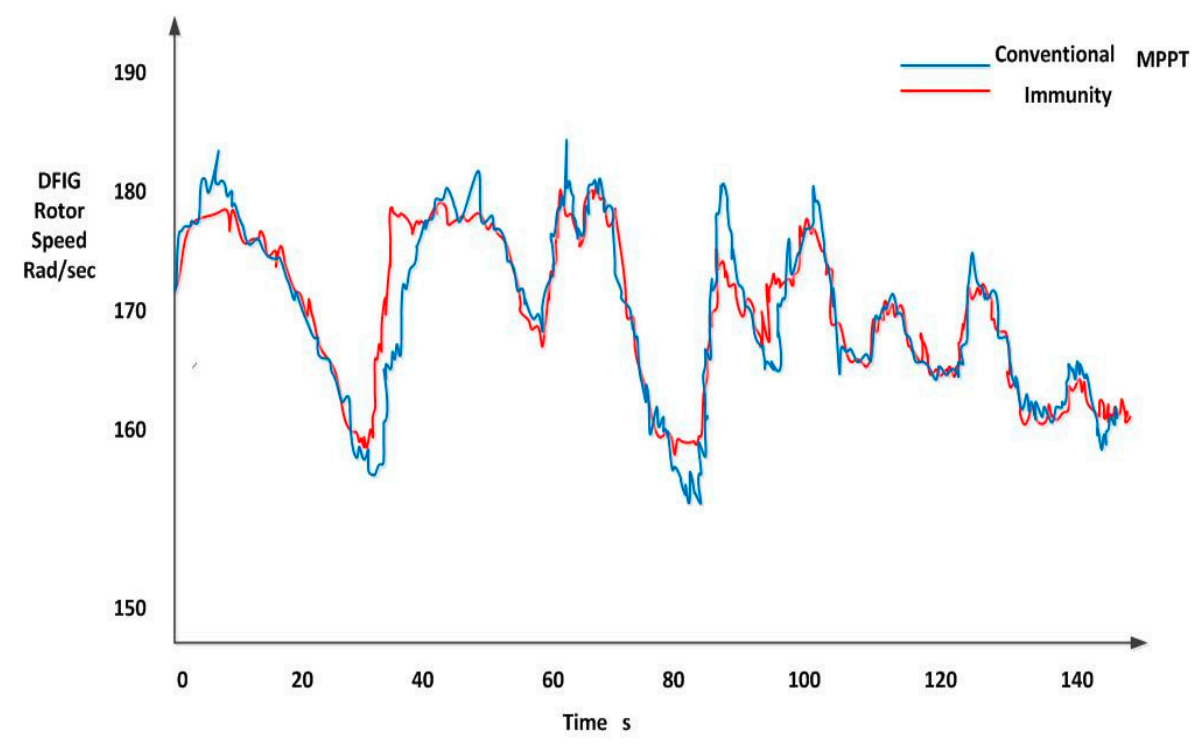

Figure 14. The DFIG rotor speed for both conventional and AI Eco-MPPT strategies.

Table 2. MATLAB execution time for different techniques.

\begin{tabular}{cc}
\hline \multicolumn{2}{c}{ Execution Time } \\
\hline Fuzzy MPPT controller & $14.11 \mathrm{~s}$ \\
Conventional Method & $10.333 \mathrm{~s}$ \\
AIS MPPT & $11.66 \mathrm{~s}$ \\
AISE & $13.22 \mathrm{~s}$ \\
ASO & $2.72 \mathrm{~s}$ \\
Total AI time & $\sim 23 \mathrm{~s}$ \\
\hline
\end{tabular}




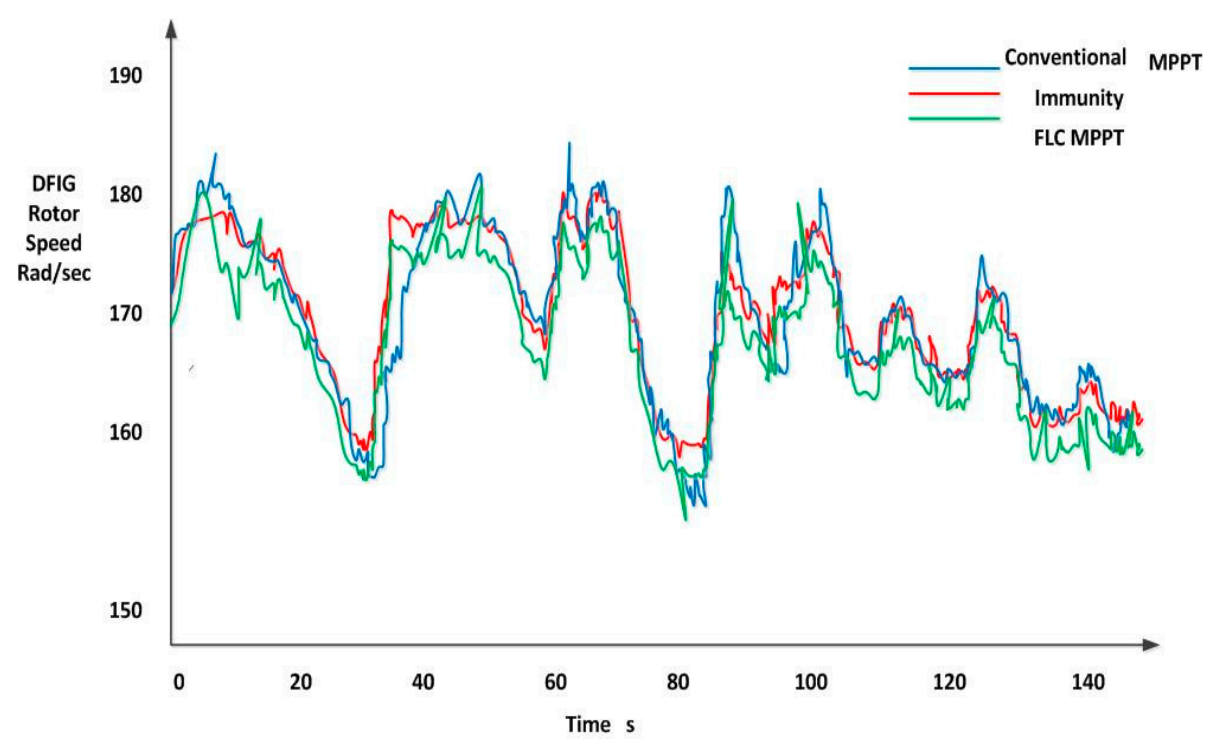

Figure 15. The comparison of DFIG rotor speed for different types of Eco-MPPT strategies (Conventional, AI and FLC).

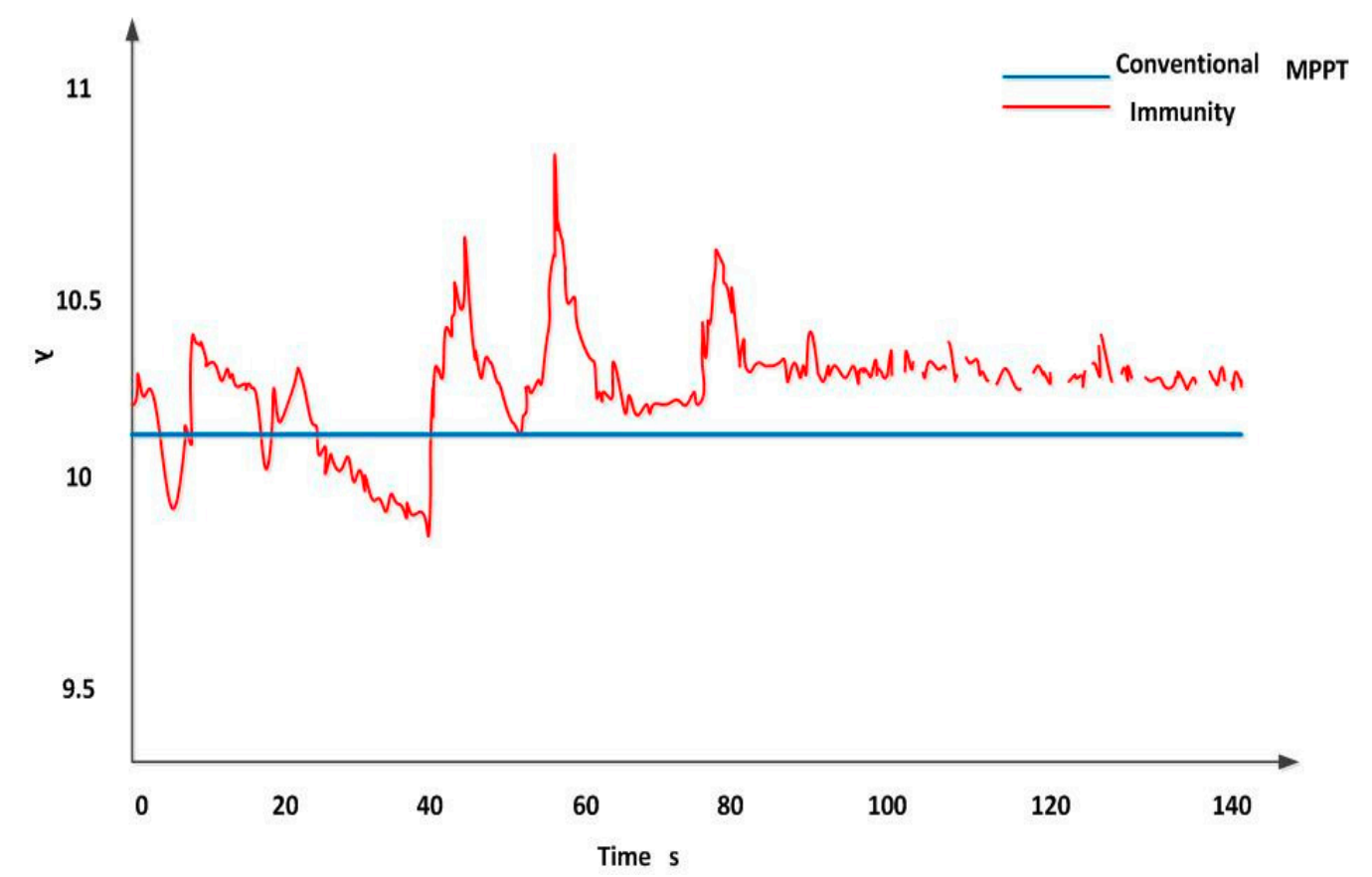

Figure 16. The comparison of TSR for both MPPT strategies.

As illustrated in Figure 17, the difference between the standard electrical generated output power and its MPPT developed equivalent is studied. The environmental impact and the reduction in $\mathrm{CO}_{2}$ emission is calculated. The reduction in $\mathrm{CO}_{2}$ emission for Eco-MPPT controlled generation is studied, compared to the fossil fuel and wind electrical generation in standard case. It is calculated utilizing Equation (39):

$$
R d_{\mathrm{CO}_{2} e m}=\left(S 1_{\mathrm{CO}_{2} e m}-S 2_{\mathrm{CO}_{2} e m}\right) \times M W h_{g n}
$$

where $R d_{\mathrm{CO}_{2} \text { em }}$ is the reduction in $\mathrm{CO}_{2}$ emission (in $\mathrm{kg} \mathrm{CO}$ ). The $S 1_{\mathrm{CO}_{2} \text { em }}$ and $S 2_{\mathrm{CO}_{2} \mathrm{em}}$ are the $\mathrm{CO}_{2}$ emissions in $\mathrm{kgCO}_{2} / \mathrm{MWh}$ for electrical source 1 which is the replaced source and the used renewable one. $M W h_{g n}$ is the generated electrical energy in $\mathrm{MWh}$. The $\mathrm{CO}_{2}$ emission for fossil fuel varies from 750 to $1100 \mathrm{kgCO}_{2} / \mathrm{MWh}$, while $\mathrm{CO}_{2}$ emission for wind electrical generation varies between 15 and 
$40 \mathrm{kgCO}_{2} / \mathrm{MWh}$. In this research, the considered values for the $\mathrm{CO}_{2}$ emission from fossil fuel and wind generation are 880 and $30 \mathrm{kgCO}_{2} / \mathrm{MWh}$, respectively.

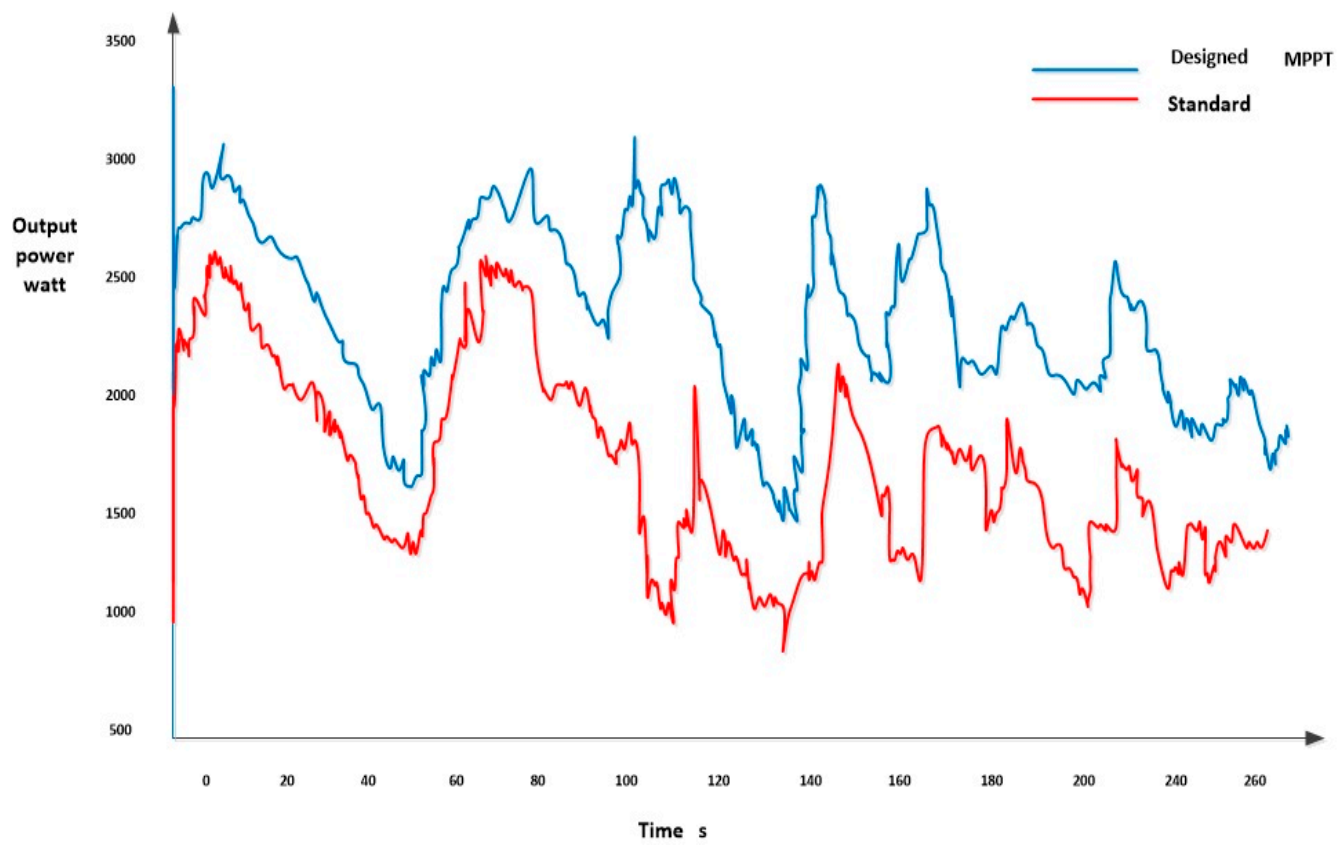

Figure 17. The difference between DFIG output power in both standard and designed Eco-MPPT cases.

As calculated in Figure 17, the average energy per day in normal operation case is around $42 \mathrm{kWh}$, while in Eco-MPPT case is $60 \mathrm{kWh}$.

Table 3 and Figure 18 illustrate the $\mathrm{CO}_{2}$ emission in $\mathrm{kgCO}_{2}$ for the generated average power in both normal and Eco-MPPT cases and their equivalence in fossil fuel electrical generation case.

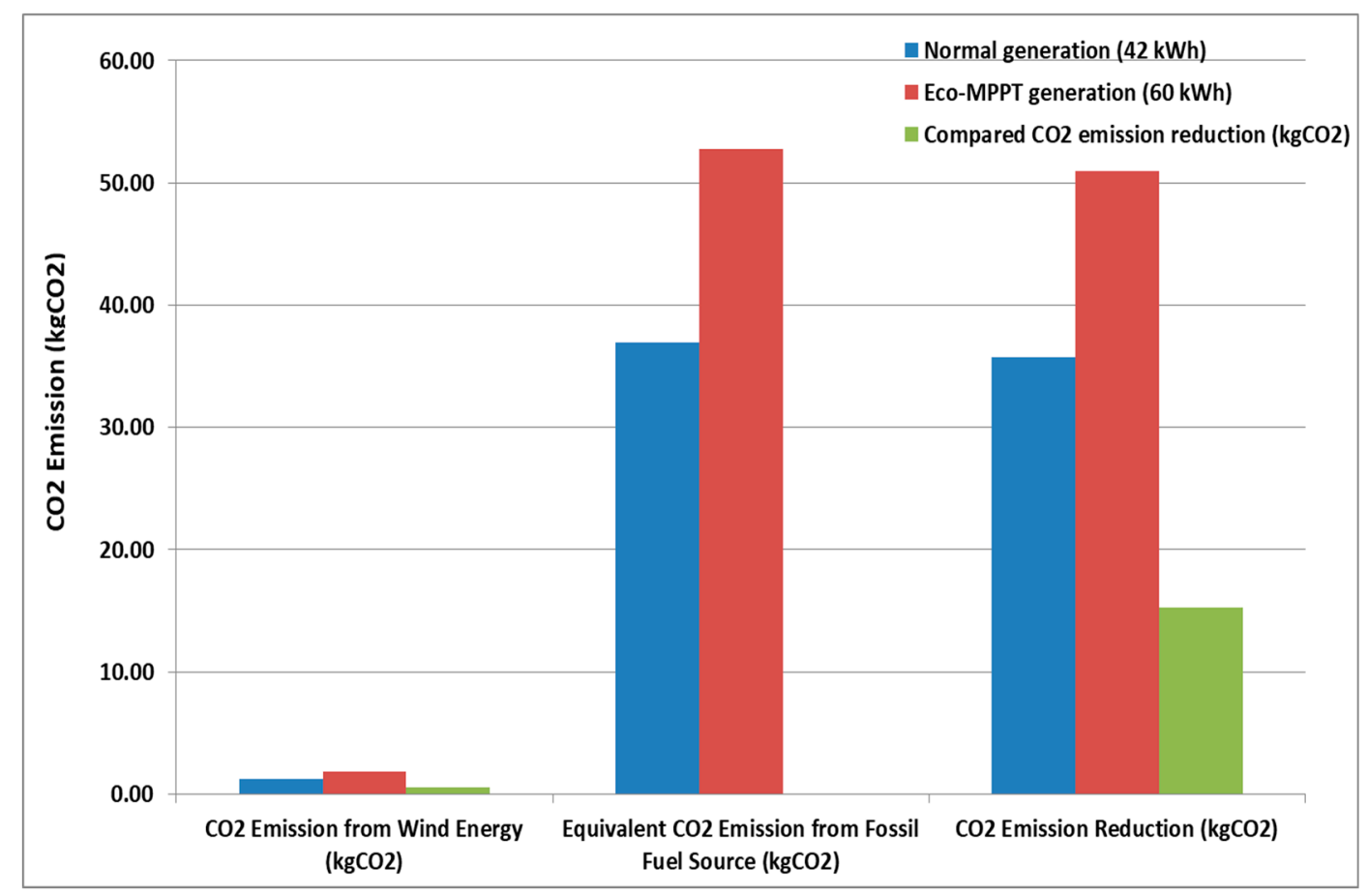

Figure 18. The $\mathrm{CO}_{2}$ emission and reduction in normal and Eco-MPPT cases compared to fossil fuel case. 
Table 3. The $\mathrm{CO}_{2}$ emission and reduction in normal and Eco-MPPT cases compared to fossil fuel case.

\begin{tabular}{|c|c|c|c|}
\hline & $\begin{array}{c}\mathrm{CO}_{2} \text { Emission from } \\
\text { Wind Energy }\left(\mathrm{kgCO}_{2}\right)\end{array}$ & $\begin{array}{l}\mathrm{CO}_{2} \text { Emission from Fossil } \\
\text { Fuel Source }\left(\mathrm{kgCO}_{2}\right)\end{array}$ & $\begin{array}{c}\mathrm{CO}_{2} \text { Emission } \\
\text { Reduction }\left(\mathrm{kgCO}_{2}\right)\end{array}$ \\
\hline Normal generation (42 kWh) & 1.26 & 36.96 & 35.7 \\
\hline Eco-MPPT generation (60 kWh) & 1.8 & 52.8 & 51 \\
\hline $\begin{array}{l}\text { Compared } \mathrm{CO}_{2} \text { emission } \\
\text { reduction }\left(\mathrm{kgCO}_{2}\right)\end{array}$ & 0.54 & & 15.3 \\
\hline
\end{tabular}

Finally, since the executed time is considered sufficient, the proposed controller can be implemented using FPGA.

\section{Conclusions}

The work presented in this paper aimed to introduce the control of Eco-Maximum Power Point Tracking technique for a wind system. The advanced control consists of two parts: the first part is based on the Artificial Immunity Maximum Power Point Technique AI MPPT while the second part is based on the Input-Output decoupling with asymptotic tracking technique. A significant advantage of the proposed intelligent controller is that it generates the same electrical power as the classical MPPT method, as it reduces the size of the power converter. It decouples the system parameters to expedites the control of non-linear differential systems and supports applying direct digital control techniques while achieving asymptotic tracking. The non-linear asymptotic output tracking technique ensures the reproduction of the rotor direct and quadratic current that converge to the reference signal generated from the Artificial Immunity controller. The wind speed estimation is executed through two operations. First, the mechanical power is estimated via the DFIG rotor speed adaptive model and the electromagnetic reference. Then, the Artificial Immunity controller uses the estimated mechanical power values of the generated wind speed. The MATLAB program is used to simulate and test the proposed technique. The simulation results of AI Eco-MPPT show that this approach has better performance compared to the classical method and the fuzzy logic technique that uses both output power and estimation of the overall power losses. The results of the non-linear controller succeeded in reproducing an output signal that coincides with the required reference signal. It is also shown that the system has a compelling performance under disturbance such as wind variation. The AI controller has been programmed in c code using embedded MATLAB function in MATLAB (Simulink) software. The FPGA implementation for the proposed controller is very promising as it can offer a high-speed operation (>150 MHz), which matches with a real time application. The low power consumption, very fast I/O ports and high dynamic response are more advantages that can be delivered from recent FPGA chips. In addition, the FPGA chips can offer the essential hardware resources for MPPT techniques such as dedicated hardware multipliers, more than 30018 bit $\times 18$ bit multipliers. A larger RAMs blocks ( $>64 \mathrm{Mb}$ ) and high performance embedded processor core can also be delivered from FPGA hardware platforms. Moreover, FPGA can provide an accurate performance for MPPT techniques because it affords a high bit resolution. Accordingly, FPGA is considered as powerful candidate for AI EMPPT implementation. The environmental impact and $\mathrm{CO}_{2}$ emission reduction due to the Eco-MPPT was also studied to indicate that Eco-MPPT operation reduces around $30 \% \mathrm{CO}_{2}$ emission compared to normal operation case of DFIG wind turbine. As for future work, the authors will investigate the ability of conducting a digital control design instead of the classical emulation control for this application. Regarding the control theory, the work in $[68,69]$ could help in analyzing the targeted problem.

Author Contributions: The four authors contribute in the whole work. Conceptualization, M.H., N.H.E.-A. and H.H.I.; Formal analysis, M.H.; Investigation, A.B.; Methodology, M.H., N.H.E.-A. and H.H.I.; Project administration, N.H.E.-A. and A.B.; Software, M.H. and H.H.I.; Supervision, N.H.E.-A., H.H.I. and A.B.; Validation, A.B.; Writing-original draft, M.H. and H.H.I.; Writing—review \& editing, N.H.E.-A. and A.B.

Funding: This research received no external funding. 
Acknowledgments: This search was conducted while the first author was studying her phd under the supervision of professor Salvator Monaco from Sapienza University of Rome.

Conflicts of Interest: The authors declare no conflicts of interest.

\section{Nomenclature}

$R_{S} \quad$ Stator winding resistance

$R_{r} \quad$ Rotor winding resistance

$\lambda_{s d} \quad$ Flux linkage of the stator in the direct frame

$\lambda_{s q} \quad$ Flux linkage of the stator in the quadratic frame

$W_{S} \quad$ Rotational speed of the synchronous reference frame

$W_{r} \quad$ The rotor reference frame rotating

$V_{s d} \quad$ Stator direct voltage

$V_{s q} \quad$ Stator quadratic voltage

$i_{s d} \quad$ Stator direct current

$i_{s q} \quad$ Stator quadratic current

$L_{S} \quad$ Stator Winding Inductance

$L_{r} \quad$ Rotor Winding Inductance

M Mutual Inductance

$V_{r d} \quad$ Direct rotor voltage

$V_{r q} \quad$ Rotor voltage with respect to quadratic frame

$i_{r d} \quad$ Direct rotor current

$i_{r q} \quad$ Quadratic rotor current

$\lambda_{r d} \quad$ Flux linkage of the rotor in the direct frame

$\lambda_{r q} \quad$ Flux linkage of the rotor in the quadratic frame

J Moment of inertia

$C_{m} \quad$ Mechanical torque

$C_{e} \quad$ Electromagnetic torque

$P \quad$ Number of pole pairs

$v_{w m} \quad$ Wind speed

$P_{m} \quad$ Mechanical power generated by the turbine

$\rho \quad$ Density of the air in $\mathrm{kg} / \mathrm{m}^{3}$

A Area swept by blade in $\mathrm{m}^{2}$

$R \quad$ Radius of the blade in $\mathrm{m}$

$C_{p} \quad$ Power coefficient

$\beta \quad$ Blade pitch angle

$\lambda \quad$ Tip-speed-ratio

$Q_{s} \quad$ Reactive power

$\Omega_{r} \quad$ Rotational speed of the wind turbine in $\mathrm{rad} / \mathrm{s}$.

$\Omega_{m}^{*} \quad$ Reference rotational speed of DFIG in $\mathrm{rad} / \mathrm{s}$

$\Omega_{r}^{*} \quad$ Optimal speed of the turbine

$g \quad$ Gearbox ratio

$c_{f} \quad$ Friction coefficient

$\hat{P}_{m} \quad$ Estimated mechanical power

$c_{e}^{r e f} \quad$ Reference electromagnetic torque

$c_{p}^{\text {opt }} \quad$ Optimal Power coefficient

$\hat{\Omega_{m}} \quad$ Estimated DFIG rotor's speed

$P_{\text {loss }, g B}$ Power losses in the gearbox 


\section{References}

1. Bañosa, R.; Manzano-Agugliarob, F.; Montoyab, F.G.; Gila, C.; Alcaydeb, A.; Gómezc, J. Optimization methods applied to renewable and sustainable energy; A review. Renew. Sustain. Energy Rev. 2011, 15, 1753-1766. [CrossRef]

2. Yaramasu, V.; Dekka, A.; Durán, M.J.; Kouro, S.; Wum, B. PMSG-based wind energy conversion systems: Survey on power converters. IET Electr. Power Appl. 2017, 11, 956-968. [CrossRef]

3. Gonçalves, P.F.C.; Cruz, G.M.A.; Mendes, A.M.S.; Abadi, M.B. Fault tolerant predictive power control for wind energy application. IET Electr. Power Appl. 2017, 11, 969-980. [CrossRef]

4. Anaya-Lara, O. Wind Energy Generation: Modelling and Control; John Wiley and Sons: New York, NY, USA, 2009.

5. Aho, J.; Buckspan, A.; Laks, J.; Fleming, P.; Jeong, Y.; Dunne, F.; Churchfield, M.; Pao, L.; Johnson, K. A tutorial of wind turbine control for supporting grid frequency through active power control. In Proceedings of the 2012 American Control Conference (ACC), Montreal, QC, Canada, 27-29 June 2012; pp. 27-29.

6. Gonzralez, G.; Carranza, O. Maximum power point tracking with reduced mechanical stress applied to wind energy conversion systems. Appl. Energy 2010, 87, 2304-2312. [CrossRef]

7. Hong-Hee, L.; Phan, Q.D.; Le, M.P.; Le, D.K.; Nguyen, H.N. A new fuzzy logic approach for control system of wind turbine with doubly fed induction generator. In Proceedings of the International Forum on Strategic Technology 2010, Ulsan, Korea, 13-15 October 2010.

8. Lee, D.; Park, Y.G.; Park, J.B.; Roh, J.H. Very Short-Term Wind Power Ensemble Forecasting without Numerical Weather Prediction through the Predictor Design. J. Electr. Eng. Technol. 2017, 12, 2177-2186.

9. Renewable 2017. Available online: https://www.iea.org/publications/renewables2017/ (accessed on 30 June 2018).

10. $\mathrm{Xu}, \mathrm{Z}$.; $\mathrm{Hu}, \mathrm{Q}$; Ehsani, M. Estimation of effective wind speed for fixed speed wind turbines based on frequency domain data fusion. IEEE Trans. Sustain. Energy 2012, 3, 57-64. [CrossRef]

11. Hussein, M.M.; Senjyu, T.; Orabi, M.; Hamada, M.M. Control of a Stand-Alone Variable Speed Wind Energy Supply System. Appl. Sci. 2013, 3, 437-456. [CrossRef]

12. Meyer, D.G.; Srinivasan, S.; Semrau, G. Dynamic wind estimation based control for small wind turbines. Renew. Energy 2013, 50, 259-267. [CrossRef]

13. Munteanu, I.; Bratcu, A.I.; Cutululis, N.A.; Ceanga, E. Optimal Control of Wind Energy Systems towards a Global Approach, 1st ed.; Springer: London, UK, 2008.

14. Munteanu, I.; Besan, G. Control-based strategy for effective wind speed estimation in wind turbines. In Proceedings of the 19th World Congress on International Federation of Automatic Control, Cape Town, South Africa, 24-29 August 2014; Volume 47, pp. 6776-6781. [CrossRef]

15. Rajendran, S.; Jena, D. Variable speed wind turbine for maximum power capture using adaptive fuzzy integral sliding mode control. J. Mod. Power Syst. Clean Energy 2014, 2, 114-125. [CrossRef]

16. Wang, Q.; Chang, L. An intelligent maximum power extraction algorithm for inverter-based variable speed wind turbine systems. IEEE Trans Power Electron. 2004, 19, 1242-1249. [CrossRef]

17. Kusiak, A.; Zheng, H.; Song, Z. Short-term prediction of wind farm power: a data mining approach. IEEE Trans. Energy Convers. 2009, 24, 125-135. [CrossRef]

18. Li, S.; Wunsch, D.C.; O'Hair, E.A.; Giesselmann, M.G. Using neural networks to estimate wind turbine power generation. IEEE Trans. Energy Convers. 2001, 16, 267-282.

19. Kitajima, T.; Yasuno, T. Output Prediction of Wind Power Generation System Using Complex-valued Neural Network. In Proceedings of the SICE Annual Conference 2010, Taipei, Taiwan, 18-21 August 2010; pp. 3610-3613.

20. Alberto, L.; Cuatzin, H.G. Fuzzy Proportional Integral Control for a $1.5 \mathrm{MW}$ Wind Turbine. Rev. Univ. Telecomun. Inf. Control 2012, 1, 5-6.

21. Ahmed, O.A.; Ahmed, A.A. Control of Wind Turbine for Variable Speed Based on Fuzzy-PID Controller. SUST J. Eng. Comput. Sci. (JECS) 2017, 18, 40-51.

22. Rahman, M.M.; A-Rahim, A.H.M. An efficient wind speed sensor-less MPPT controller using adaptive neuro-fuzzy inference system. In Proceedings of the 2015 International Conference on Advances in Electrical Engineering (ICAEE), Dhaka, Bangladesh, 17-19 December 2015; pp. 230-233. 
23. Mohandes, M.; Rehman, S.; Rahman, S.M. Estimation of wind speed profile using adaptive neuro-fuzzy inference system (ANFIS). Appl. Energy 2011, 88, 402-432. [CrossRef]

24. Tiwari, A.; Shewale, A.; Lokhande, N. Comparison of various Wind Turbine Generators. Multidiscip. J. Res. Eng. Technol. 2011, 1, 129-135.

25. Pena, R.; Clare, J.C.; Asher, G.M. Doubly fed induction generator using back-to-back PWM converters and its application to variablespeed wind-energy generation. IEE Proc.-Electr. Appl. 1996, 143, 231-241. [CrossRef]

26. Ekanayake, J.B.; Holdsworth, L.; Wu, X.G.; Jenkins, N. Dynamic modeling of doubly fed induction generator wind turbine. IEEE Trans. Power Syst. 2003, 18, 803-809. [CrossRef]

27. Vas, P. Sensorless Vector and Direct Torque Control; Oxford University Press: New York, NY, USA, 1998.

28. Miller, N.W.; Sanchez-Gasca, J.J.; Price, W.W.; Delmerico, R.W. Dynamic modeling of GE 1.5 and 3.6 MW wind turbine-generators for stability simulations. In Proceedings of the 2003 IEEE Power Engineering Society General Meeting (IEEE Cat. No.03CH37491), Toronto, ON, Canada, 13-17 July 2003; pp. 1977-1983.

29. Abd El-Hamid, M.A.; El-Amary, N.H.; Mansour, M.M. Micro Grid Studies due to Fault Occurance using Immunity Technique. In Proceedings of the 11th IASTED European Conference on Power and Energy Systems, Napoli, Italy, 25-27 June 2012; pp. 20-25.

30. Wang, X.; Gao, X.; Ovaska, S. Artificial Immune Optimization Methods and Applications-A Survey. In Proceedings of the 2004 IEEE International Conference on Systems, Man and Cybernetics (IEEE Cat. No.04CH37583), The Hague, Holland, 10-13 October 2004; pp. 3415-3420.

31. Abd El-Hamid, M.A. Controlling Robotic Arm Assisted in Knee Surgery Utilizing Artificial Immunity Technique. In Proceedings of the UKSIM 2013 the IEEE international conference on modeling and simulation, Cambridge, UK, 10-12 April 2013.

32. Abd El Hamied, M.A. Tracking and Controlling Maximum Power Point Utilizing Artificial Intelligent system. In Proceedings of the 2015 IEEE International Conference on Smart City/SocialCom/SustainCom (SmartCity), Chengdu, China, 19-21 December 2015.

33. Abd El-Hamid, M.A.; El-Amary, N.H. Voltage Instability Prediction Using Artificial Immunity Technique. Int. J. Sci. Eng. Res. 2013, 4, 559-593.

34. Dadone, A.; Dambrosio, L. Estimator based adaptive fuzzy logic control technique for a wind turbine-generator system. Energy Convers. Manag. 2003, 44, 135-153. [CrossRef]

35. Angeline, K.R.; Yadlapati, S.K.B. Modelling and Simulation of ANFIS Controlled Doubly FED Induction Generator Based Wind Energy System for Performance Enhancement. Int. Sci. Press IJCTA 2017, 10, 61-73.

36. Montoya, F.G.; Manzano-Agugliaro, F.; Lropez-Mrarquez, S.; Hernrandez-Escobedo, Q.; Gil, C. Wind turbine selection for wind farm layout using multiobjective evolutionary algorithms. Expert Syst. Appl. 2014, 41, 6585-6595. [CrossRef]

37. Barakati, S.M.; Kazerani, M.; Aplevich, J.D. Maximum power tracking control for a wind turbine system including a matrix converter. IEEE Trans. Energy Convers. 2009, 24, 705-713. [CrossRef]

38. Hong, C.-M.; Ou, T.-C.; Lu, K.-H. Development of intelligent MPPT (maximum power point tracking) control for a grid-connected hybrid power generation system. Energy 2013, 50, 270-279. [CrossRef]

39. Simoes, M.G.; Bose, B.K.; Spiegel, R.J. Design and performance evaluation of a fuzzy-logic-based variable-speed wind generation system. IEEE Trans. Ind. Appl. 1997, 33, 956-965. [CrossRef]

40. Belmokhtar, K.; Doumbia, M.L.; Agbossou, K. Novel fuzzy logic based sensorless maximum power point tracking strategy for wind turbine systems driven DFIG (doubly-fed induction generator). Energy 2014, 76, 679-693. [CrossRef]

41. Cardenas, R.; Pena, R. Sensorless vector control of induction machines for variable-speed wind energy applications. IEEE Trans. Energy Convers. 2004, 19, 196-205. [CrossRef]

42. Kumar, A.; Satwase, A.; Mishra, R. Transient Behavior of Doubly Fed Induction Generator Using Simulink Model in Wind Energy Conversion System. Int J. Innov. Res. Sci. Eng. Technol. 2015, 4, 450-454.

43. Banakar, H.; Luo, C.; Ooi, B.T. Steady-state stability analysis of doubly-fed induction generators under decoupled PQ control. IEE Proc.-Electr. Power Appl. 2006, 153, 300-306. [CrossRef]

44. Marques, G.D.; Sousa, D.M. New Sensorless Rotor Position Estimator of a DFIG Based on Torque Calculations Stability Study. IEEE Trans. Energy Convers. 2012, 27, 196-202. [CrossRef] 
45. Nelson, R.H.; Lipo, T.A.; Krause, P.C. Stability analysis of a symmetrical induction machine. IEEE Trans. Power Appar. Syst. 1969, PAS-88, 1710-1717. [CrossRef]

46. Amin, I.K.; Uddin, M.N. Nonlinear Control Operation of DFIG based WECS with Stability Analysis. In Proceedings of the 2017 IEEE Industry Applications Society Annual Meeting, Cincinnati, OH, USA, 1-5 October 2017; pp. 1-8.

47. Cheikh, R.; Belmili, H. Nonlinear Control of a Grid-Connected Double Fed Induction Generator Based Vertical Axis Wind Turbine: A Residential Application. Int. J. Electr. Energy 2016, 4, 4.

48. Boudjema, Z.; Meroufel, A.; Djerriri, Y. Nonlinear control of a doubly fed induction generator for wind energy conversion. Carpath. J. Electron. Comput. Eng. 2013, 6, 28-35.

49. Abad, G.; Lopez, J.; Rodriguez, M.; Marroyo, L.; Iwanski, G. Doubly Fed Induction Machine: Modeling and Control for Wind Energy Generation, 1st ed.; John Wiley and Sons, Inc.: Hobokes, NJ, USA, 2011.

50. Hansen, A.D.; Srensen, P.; Iov, F.; Blaabjerg, F. Control of variable speed wind turbines with doubly-fed induction generators. Wind Eng. 2004, 28, 411-434. [CrossRef]

51. Alrifai, M.; Mohamed, Z.; Rayan, M. Feedback Linearization Controller for a Wind Energy Power System. In Proceedings of the 24th Mediterranean Conference on Control and Automation, Athens, Greece, 21-24 June 2016.

52. Chen, J.; Jiang, L.; Yao, W.; Wu, Q.H. Perturbation estimation based nonlinear adaptive control of a full-rated converter wind turbine for fault ride-through capability enhancement. IEEE Trans. Power Syst. 2014, 29, 2733-2743.

53. Xiang, D.; Ran, L.; Tavner, P.J.; Yang, S. Control of a doubly fed induction generator in a wind turbine during grid fault ride-through. IEEE Trans. Energy Convers. 2006, 21, 652-662. [CrossRef]

54. Lopez, J.; Sanchis, P.; Roboam, X.; Marroyo, L. Dynamic behavior of the doubly fed induction generator during three-phase voltage dips. IEEE Trans. Energy Convers. 2007, 22, 709-717. [CrossRef]

55. Khemiri, N.; Khedher, A.; Mimouni, M.F. Wind Energy Conversion System using DFIG Controlled by Backstep-ping and Sliding Mode. Int. J. Renew. Energy Res. 2012, 2, 421-430.

56. Ouari, K.; Rekioua, T.; Ouhrouche, M.A. Non Linear Predictive Controller for Wind Energy Conversion System. In Proceedings of the International Renewable Energy Congress IREC, Sousse, Tunisia, 5-7 November 2010; pp. 220-226.

57. Isidori, A.; Krener, A.j.; Gori-Giorgi, C.; Monaco, S. Non linear decoupling via feedback: A differential geometric approach. IEEE Trans. Autom. Control 1981, 26, 331-345. [CrossRef]

58. Wei, Q.; Wei, Z.; Aller, J.M.; Harley, R.G. Wind speed estimation based sensorless output maximization control for a wind turbine driving a DFIG. IEEE Trans. Power Electron. 2008, 23, 1156-1169.

59. Ltifi, A.; Ghariani, M.; Neji, R. Comparison of Two Techniques for Control Nonlinear Systems: The PI Regulator and Sliding Mode Control. In Proceedings of the International Conference on Control, Engineering Technology, Sousse, Tunisia, 22-25 March 2014.

60. Isidori, A. Nonlinear Control Systems, 3rd ed.; Springer: London, UK, 1995; ISBN 978-3-540-19916-8.

61. Huimin, L.; Yujie, L.; Min, C.; Hyoungseop, K.; Seiichi, S. Brain Intelligence: Go beyond Artificial Intelligence. Mob. Netw. Appl. 2018, 23, 368-375. [CrossRef]

62. Chekired, F.; Mellit, A.; Kalogirou, S.A.; Larbes, C. Intelligent maximum power point trackers for photovoltaic applications using FPGA chip: A comparative study. Sol. Energy 2014, 101, 83-99. [CrossRef]

63. Adel, M.; Kalogirou, S.A. MPPT-based artificial intelligence techniques for photovoltaic systems and its implementation into field programmable gate array chips: Review of current status and future perspectives. Energy Elsevier 2014, 70, 1-21. [CrossRef]

64. Dileep, G.; Singh, S.N. Maximum power point tracking of solar photovoltaic system using modified perturbation and observation method. Renew. Sustain. Energy Rev. 2015, 50, 109-129. [CrossRef]

65. Karim, K.; Cherif, L.; Naeem, R.; Moussaab, B.; Zine elabadine, D. Bat algorithm based maximum power point tracking for photovoltaic system under partial shading conditions. Sol. Energy 2017, 158, 490-503.

66. Accetta, A.; Di Piazza, M.C.; Tona, G.L.; Luna, M.; Pucci, M. A high-performance FPGA-based virtual anemometer for MPPT of wind energy conversion systems. In Proceedings of the IEEE 26th International Symposium on Industrial Electronics (ISIE), Edinburgh, UK, 19-21 June 2017; pp. 926-933.

67. Youssef, A.; ElTelbany, M.; Zekry, A. Reconfigurable generic FPGA implementation of fuzzy logic controller for MPPT of PV systems. Renew. Sustain. Energy Rev. 2018, 82, 1313-1319. [CrossRef] 
68. Mattioni, M.; Monaco, S.; Normand-Cyrot, D. Sampled-data reduction of nonlinear input-delayed dynamics. IEEE Control Syst. Lett. (L-CSS) 2017, 1, 116-121. [CrossRef]

69. Monaco, S.; Normand-Cyrot, D.; Mattioni, M. Sampled-data stabilization of nonlinear dynamics with input delays through Immersion and Invariance. IEEE Trans. Autom. Control 2017, 62, 2561-2567. [CrossRef] 